O
O
N
o
Z

INTEROPERABILITY AS A

TOOL FOR COMPETITION

REGULATION

\title{
IANBROWN
}


Interoperability is a technical mechanism for computing systems to work together even if they are from competing firms. An interoperability requirement for large online platforms has been suggested by the European Commission as one ex ante (up-front rule) mechanism in its proposed Digital Markets Act (DMA), as a way to encourage competition. The policy goal is to increase choice and quality for users, and the ability of competitors to succeed with better services. The application would be to the largest online platforms, such as Facebook, Google, Amazon, smartphone operating systems (e.g. Android/iOS), and their ancillary services, such as payment and app stores.

This report analyses up-front interoperability requirements as a pro-competition policy tool for regulating large online platforms, exploring the economic and social rationales and possible regulatory mechanisms. It is based on a synthesis of recent comprehensive policy reviews of digital competition in major industrialised economies, and related academic literature, focusing on areas of emerging consensus while noting important disagreements. It draws particularly on the Vestager, Furman and Stigler reviews, and the UK Competition and Markets Authority's study on online platforms and digital advertising. It also draws on interviews with software developers, platform operators, government officials, and civil society experts working in this field.

Intended audience: this report is intended to support civil society and parliamentary groups developing positions on ex ante competition rules in the EU's proposed Digital Markets Act, and digital competition reforms in other jurisdictions.

Acknowledgements: The author thanks Chloé Berthélémy, Astor Carlberg, Ignacio Castro, Kevin Coates, Jon Crowcroft, Cory Doctorow, Gerben (including for drawing figures 1 and 2), Liza Lovdahl Gormsen, Hamed Haddadi, Bernie Hogan, Orla Lynskey, Chris Marsden, Rob Nicholls, Jan Penfrat, Christoph Schmon, Jonathan Todd, Kasia Szymielewicz, Tommaso Valletti, Simonetta Vezzoso and Lorna Woods for their advice.

Funding: This research was supported by the Open Society Foundations Information Programme. All unattributed analysis and opinions expressed are entirely the author's own.

\section{About the author}

Dr. Ian Brown is visiting CyberBRICS professor at Fundação Getulio Vargas (FGV) Law School in Rio de Janeiro. He was previously Principal Scientific Officer at the UK government's Department for Digital, Culture, Media and Sport; Professor of Information Security and Privacy at the University of Oxford's Internet Institute; and a Knowledge Exchange Fellow with the Commonwealth Secretariat and UK National Crime Agency. His books include Cybersecurity for Elections (2020, Commonwealth 
Secretariat, with Marsden/Lee/Veale), Regulating Code (2013, MIT Press, with Marsden), and Research Handbook on Governance of the Internet (ed., 2013, Edward Elgar). His PhD in computer science is from University College London. 


\section{Contents}

Figures 4

Introduction $\quad 5$

What would interoperability look like? $\quad 7$

High levels of concentration in digital platforms $\quad 14$

Economic impacts of interoperability 16

$\begin{array}{ll}\text { Multi-homing and tipping } & 18\end{array}$

Gatekeepers, conglomerates and ecosystems 20

Complementary innovation and homogenisation 23

$\begin{array}{ll}\text { Static vs dynamic effects } & 25\end{array}$

Social impacts of interoperability $\quad 27$

Platforms as essential social infrastructure $\quad 29$

Media pluralism and diversity 31

Privacy and data protection 33

$\begin{array}{ll}\text { Content moderation } & 39\end{array}$

Environmental impact $\quad 43$

Digital sovereignty $\quad 44$

Existing and planned European interoperability policies $\quad 47$

Appendix 1 - Types of interoperability and example scenarios 54

Vertical and horizontal interoperability $\quad 55$

Protocol and data interoperability $\quad 56$

Detailed technical and regulatory examples 57

Straightforward within existing regulatory framework 57

New but less controversial scenarios (based on past experience from other sectors) 59

New and more challenging scenarios $\quad 60$ 


\section{Figures}

Figure 1 Connecting "gatekeeper" platforms with smaller services....................... 5

Figure 2 Network architectures............................................................... 8

Figure 3 Tweetbot and Nuzzel - two alternative apps to access Twitter ...............10

Figure 4 Twitter CEO Jack Dorsey announces the company's interoperability

project ................................................................................................ 11

Figure 5 Mastodon users can communicate via 500-character "toots" with other users on their own "instance", and on other connected instances and services....12 Figure 6 Users of other platforms' ability to post to/from Facebook

Figure 7 Combined indicative market shares of current leading two companies in selected UK digital markets ..........................................................................15

Figure 8 CMA simplified assessment of consumer harm .....................................16

Figure 9 Andrew Reed's humorous suggestion for a Twitter redesign, inspired by Google's multiple user interface interventions to promote its videoconferencing

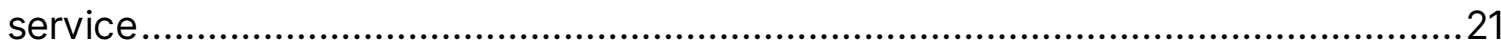

Figure 10 CMA interpretation of a selection of Google and Facebook services......22 Figure 11 TweetDelete and Thread Reader, two complementary services to Twitter

Figure 12 Facebook users in the population of the EU's 27 member states, March 2020

Figure 13 Mastodon helps new users find instances matching their content moderation preferences

Figure 14 Muller et al.'s framework model for interoperability maturity in the Building Information Modelling lifecycle... 


\section{Introduction}

Interoperability is a technical mechanism for computing systems to work together even if they are from competing firms. An interoperability requirement for the largest online "gatekeeper" platforms ${ }^{1}$ has been suggested by the European Commission as one ex ante (up-front rule) mechanism in its proposed Digital Markets Act (DMA), as a way to encourage competition. The policy goal is to increase choice and quality for users, and the ability of competitors to succeed with better services. ${ }^{2}$ The application would be to large online platforms such as social media (e.g. Facebook), search engines (e.g. Google), e-commerce marketplaces (e.g. Amazon), smartphone operating systems (e.g. Android/iOS), and their ancillary services, such as payment and app stores. Users of other services could choose to connect to friends, businesses and resources on these "gatekeeper" platforms, as shown in Figure 1.

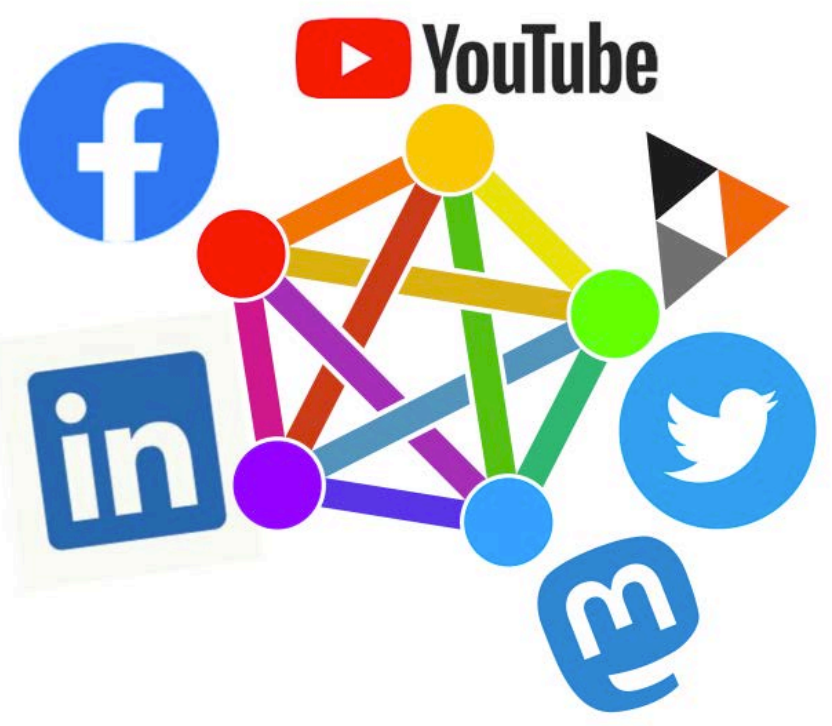

Figure 1 Connecting "gatekeeper" platforms with smaller services

\footnotetext{
${ }^{1}$ The Digital Services Act consultation defines this as "online platforms reaching a certain level of users and covering different types of services that are considered to have a particularly important impact and play a distinctive role as 'gatekeepers' to the services they provide. Since the present consultation itself inquires about the distinctive features, the impact and the potential measures, which need to be taken in relation to such platforms, this definition should be understood more as a description of possible features that identify large online platforms."

${ }^{2}$ European Commission DG Connect, The Digital Services Act package, 2 June 2020.
} 
An interoperability requirement has been recommended in varying forms by the special advisers to European Commission executive vice-president Margrethe Vestager, ${ }^{3}$ the UK's Furman ${ }^{4}$ and digital advertising ${ }^{5}$ reviews, and the US Stigler Report. This latter report concludes:

"Interoperability would facilitate ongoing competition on the merits of the user experience, rather than on the size of the installed base, and potentially stimulate robust competition... With easy interoperability, users will be free to make a real choice about which service they prefer. This will encourage new market entry and vigorous competition between providers." 6

According to civil society group European Digital Rights:

interoperability would drastically reduce the imbalance of power between platforms on the one side and individuals on the other. It would (re)em-power Internet users to interact across digital silos and allow them to choose their own online community and appropriate guidelines. An interoperability requirement would ensure that citizens do not sign up to dominant platforms just because there is no other way to communicate with their friends and participate in the social life of their local community, e.g. students at a university. It would also directly strengthen healthy competition among platforms and could even create whole new markets of online services built on top of existing platforms, such as third-party client apps or content moderation plug-ins.

Effective interoperability requirements need attention to:

a. the terms of service that largely govern individuals' interactions with platforms (as contract law);

b. intellectual property rights; ${ }^{8}$ and

c. cybersecurity laws. ${ }^{9}$

\footnotetext{
3 J Crémer, A de Montjoye and H Schweitzer, Competition policy for the digital era (Luxembourg: Publications Office of the European Union, 2019).

4 J Furman, D Coyle, A Fletcher, D McAuley and P Marsden, Unlocking Digital Competition (London: HM Treasury, 2019), pp.32-38.

${ }^{5}$ Online platforms and digital advertising (London: Competition and Markets Authority, 2020).

${ }^{6}$ Stigler Committee on Digital Platforms, Final Report, September 2019, p.118.

${ }^{7}$ EDRi, Platform Regulation Done Right, 9 April 2020, p.22.

${ }^{8}$ I Graef (2015) Mandating portability and interoperability in online social networks: regulatory and competition law issues in the European Union, Telecommunications Policy 39(6), pp.502-514.

${ }^{9}$ C Doctorow, Interoperability: Fix the Internet, Not the Tech Companies, EFF Deeplinks, 11 July 2019.
} 
Terms of service are explored by the reviews cited above. Intellectual property rights and interoperability have been analysed by Otero in her PhD thesis. ${ }^{10}$ Little attention so far has been paid to cybersecurity laws.

However, this report focuses on competition policy and regulatory issues raised by interoperability requirements, with some consideration of the resulting data protection and cybersecurity implications. While the EU's competition law framework is the main focus, including the electronic communications-specific directives, there are important interactions with data protection and consumer protection frameworks, as noted by Graef, Clifford and Valcke:

While data protection law aims to protect autonomous decision-making by data subjects but also more broadly includes the safeguarding of a secure and fair personal data processing environment, consumer protection law empowers individuals to make well-informed autonomous choices. Therefore, although consumer protection and data protection clearly overlap, as data protection applies whenever personal data are processed, it is distinct since it is not solely connected to the protection of an individual's decision-making capacity and choices. Competition law, for its part, aims to keep markets competitive so to ensure that consumers have such choices. ${ }^{11}$

The UK's Competition and Markets Authority (CMA) is no longer an EU member state regulator. However, this report draws particularly heavily on its recent market study of online platforms and digital advertising, which contains 27 detailed analytical annexes, based on a year-long market study using statutory powers to require information from nearly 120 parties, extensive internal and commissioned research, over 130 responses to two consultations, and over 150 meetings with over 60 parties. $^{12}$

\section{What would interoperability look like?}

What would large online platforms look like to a user if they were required to interoperate with other services? The simplest existing examples are mobile phone SMS text messages and email. Mobile phone users can send SMS text messages to any other user just by knowing their phone number, whichever type of phone or network they are on. The online platform equivalent would be a WhatsApp user sending a message to a Facebook Messenger, Signal or Telegram user. In computer

\footnotetext{
${ }^{10}$ B González Otero, Interoperabilidad, internet de las cosas y derecho de autor (Madrid: Reus Editorial, 2019).

${ }^{11}$ I Graef, D Clifford and P Valcke (2018) Fairness and enforcement: bridging competition, data protection, and consumer law, International Data Privacy Law, Vol. 8, No. 3, p.203.

${ }^{12}$ CMA, fn 5, p.39.
} 
networking terms, these are "federated" systems, where the mobile phone user's telephony provider is connected to other networks, as shown in Figure 2.

Email users can connect to their own email service through a Web browser, and/or an email program (like Outlook) or app running on their personal computer or smartphone. There are a small number of extremely large services such as Gmail; a very large number of much smaller services, run by organisations such as Information Society Service Providers, businesses and universities (for their customers, staff and students); and very small services run by individuals on their own Internetconnected computers, hosting accounts for themselves and friends/family members.

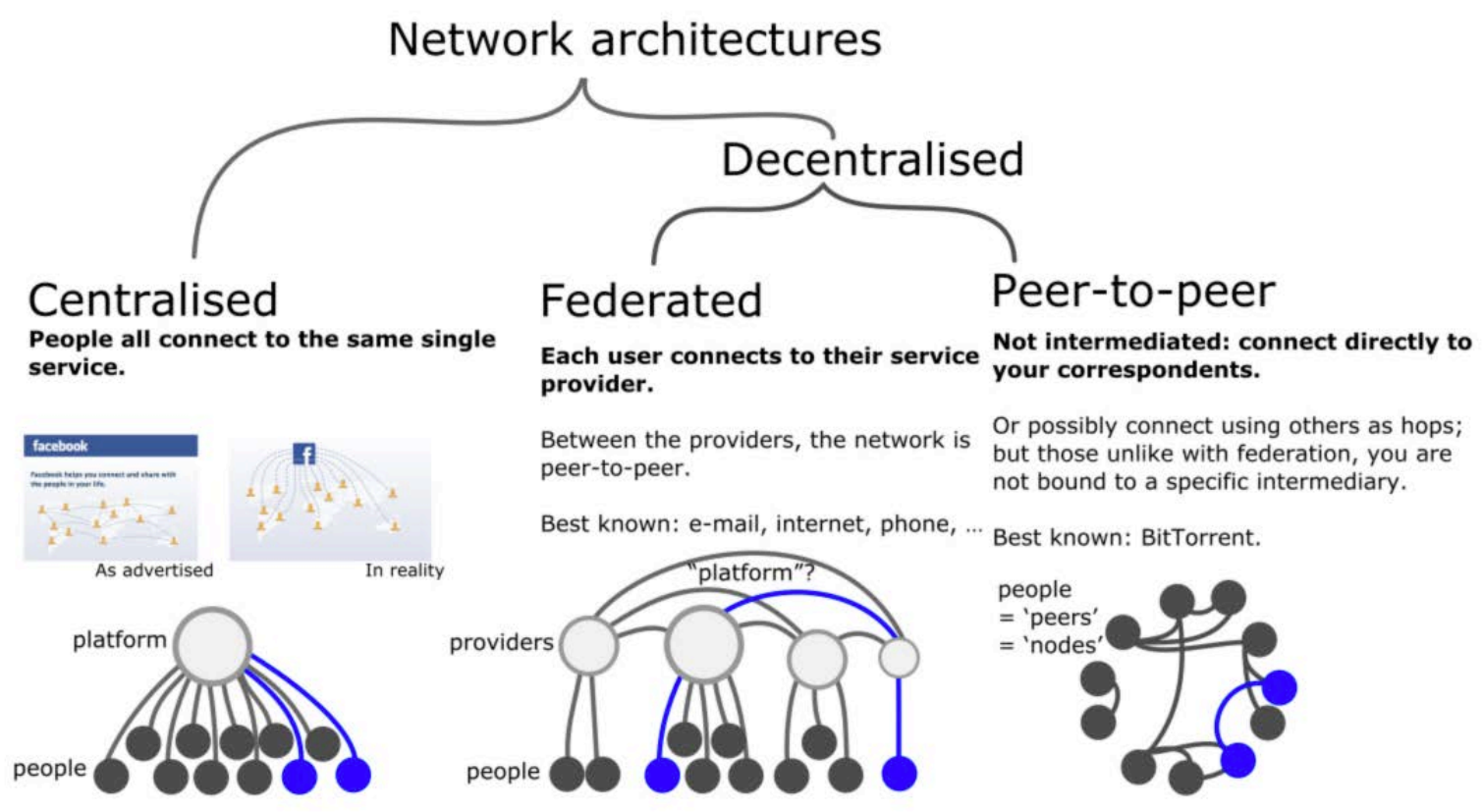

Figure 2 Network architectures

Users can send email to each other whichever their service, using the familiar email address, which contains both a username (before the @ symbol) and a service address (after it). Because all email services can connect to each other, this is known as a "federated" system (even though it contains some very large individual services). Because it does not rely on a single central service, it is "decentralised".

An equivalent interoperable social media protocol would connect very large services (such as Facebook/WhatsApp/Instagram, Twitter, and LinkedIn) with organisational 
and individually-run services. ${ }^{13}$ Users of any of these services could communicate with each other when authorised to do so, connecting as "friends" or "followers"; sending messages; sharing information such as profiles, status updates, "likes" or "retweets", location, and photos, with individuals, groups and the public; following and responding to each other's' feeds; ${ }^{14}$ and searching across all connected services. The CMA assessed the availability of such features in common social media platforms, in Table 1.

\begin{tabular}{|c|c|c|c|c|c|c|c|c|}
\hline & $\begin{array}{l}\text { Profive/ } \\
\text { Account }\end{array}$ & $\begin{array}{l}\text { Curated/ } \\
\text { Personalised } \\
\text { Feed }\end{array}$ & $\begin{array}{c}\text { Friends/ } \\
\text { Contacts/ } \\
\text { Connections }\end{array}$ & $\begin{array}{l}\text { Followers/ } \\
\text { Subscribers }\end{array}$ & $\begin{array}{l}\text { Photo } \\
\text { Sharing }\end{array}$ & $\begin{array}{l}\text { Video } \\
\text { Sharing }\end{array}$ & Comments & Messaging \\
\hline YouTube & $\checkmark$ & Recommended & $\checkmark$ & $\checkmark$ & $\checkmark$ & $\checkmark$ & $\checkmark$ & $\checkmark$ \\
\hline Facebook & $\checkmark$ & News Feed & $\checkmark$ & $\checkmark$ & $\checkmark$ & $\checkmark$ & $\checkmark$ & $\checkmark$ \\
\hline Snapchat & $\checkmark$ & Discover & $\checkmark$ & $\checkmark$ & $\checkmark$ & $\checkmark$ & & $\checkmark$ \\
\hline WhatsApp & $\checkmark$ & & $\checkmark$ & & $\checkmark$ & $\checkmark$ & & $\checkmark$ \\
\hline Instagram & $\checkmark$ & Explore & $\checkmark$ & $\checkmark$ & $\checkmark$ & $\checkmark$ & $\checkmark$ & $\checkmark$ \\
\hline Twitter & $\checkmark$ & Timeline & & $\checkmark$ & $\checkmark$ & $\checkmark$ & Replies & $\checkmark$ \\
\hline Linkedlin & $\checkmark$ & $\checkmark$ & $\checkmark$ & $\checkmark$ & $\checkmark$ & $\checkmark$ & $\checkmark$ & $\checkmark$ \\
\hline TikTok & $\checkmark$ & For You & $\checkmark$ & $\checkmark$ & & $\checkmark$ & $\checkmark$ & $\checkmark$ \\
\hline Pinterest & $\checkmark$ & $\checkmark$ & & $\checkmark$ & $\checkmark$ & $\sim$ & $\checkmark$ & $\checkmark$ \\
\hline Reddit & $\checkmark$ & Front Page & $\checkmark$ & $\checkmark$ & $\checkmark$ & $\checkmark$ & $\checkmark$ & $\checkmark$ \\
\hline Tumbr & $\checkmark$ & Dashboard & & $\checkmark$ & $\checkmark$ & $\checkmark$ & $\checkmark$ & $\checkmark$ \\
\hline
\end{tabular}

Table 1: Social media platforms' functionalities. Source: CMA (2020) p.117.

This is the functionality that is core to the major social media services used in Europe, but dominant services required to interoperate would still be able to develop new functionality that would not be standardised until it became much more common.

Twitter already enables other systems and software to connect to some of its services. Many Twitter users read and post tweets using other companies' apps, such as Tweetbot and Nuzzel (shown in Figure 3), although those apps are no longer able to access certain features, such as notifications of tweets "liked" by other users, due to changes made by Twitter in its technical interface ("Application Programming Interfaces", or APIs). Twitter is funding a small team to explore "decentralising" its

\footnotetext{
${ }^{13}$ For a visualisation, see D Hinchcliffe, Where is interoperability for social media? ZDNet, 28 February 2014.

${ }^{14}$ CMA, fn 5, pp.53-55.
} 
platform, moving towards a more email-like model, ${ }^{15}$ as shown in a tweet from CEO Jack Dorsey in Figure 4: ${ }^{16}$

Timeline

Kevin Donovan @kevindonovan

It's true for African history, too, where Ohio University and Indiana University presses are critical.

Max Ajl @maxajl

I feel that people don't always appreciate

what the "smaller" or less marquee

university presses are doing and publishing especially in the South

Tedros Adhanom Ghebreyesus ... $50 \mathrm{~d}$

I appreciate what you said, @devisridhar, about the Jan 30 public health emergency declaration. This was the key point when @who put the world on highest alert to fight \#COVID19.

World Health Organization (WHO) ... 68d Since January 30 , WHO has been calling on countries to prepare to find, test, treat and isolate every \#COVID19 patient and trace all contacts. Some, but not all, countries have followed WHO advice...

ט. Prof Chris Marsden

The Cricketer @TheCricketerMag @ @edwardscricket on the lasting affection between @BacupCC and Everton Weekes.

thecricketer.com/Topics/banner/...

t] Prof Chris Marsden

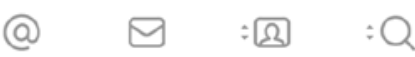

¿j

A Misinformation Regulator - 4th
July 2020
Jul 4, 8:00 am
- 15 min read -- There has been growing demand to
'do something' about online misinformation since the
2016 US Presidential election. This demand has
increased in light of Covid-19 and as this year's US ...

480 욤

THE WALL STREET JOURNAL

WSJ News Exclusive | Chinese Research Papers Raise Doubts, Fueling Global Questions About Scientific Integrity

Eva Xiao - Jul 5, 10:00 an

HONG KONG - Internationally peer-reviewed journals published more than 100 scientific research papers from China-based authors that appear to have reused identical sets of images, raising questions about the..

2 (8)

THE GUARDIAN

Facebook is out of control. If it were a country it would be North Korea | Facebook

There is no power on this earth that is capable of holding Facebook to account. No legislature, no law enforcement agency, no regulator. Congress has failed. The EU has failed. When the Federal Trade...

Figure 3 Tweetbot and Nuzzel - two alternative apps to access Twitter

${ }^{15}$ A Robertson, Twitter wants to decentralize, but decentralized social network creators don't trust it, The Verge, 12 December 2019.

${ }^{16}$ Source: Tweet by @jack, 11 December 2019. 
Twitter is funding a small independent team of up to five open source architects, engineers, and designers to develop an open and decentralized standard for social media. The goal is for Twitter to ultimately be a client of this standard.

2:13 PM · Dec 11, 2019 - Twitter for iPhone

Figure 4 Twitter CEO Jack Dorsey announces the company's interoperability project

The Mastodon social network, a Twitter-like microblogging service with over $4 \mathrm{~m}$ users, also federated with other services, already has such a structure. It allows users to create an account on one or more of hundreds of connected "instances", run mainly by individual enthusiasts. Each tweet-like "toot" can contain up to 500 characters, and has more options than Twitter relating to audience and the ability to provide a content warning.

Users can read toots from other users on the same instance, and users on other, connected instances (see Figure $5^{17}$ ) - as well as other services using the open standards body World Wide Web Consortium's (W3C) ActivityPub standard, ${ }^{18}$ such as PeerTube (a French free and decentralised alternative to video platforms, with over 200,000 videos published by 30,000 users and viewed over 10 million times ${ }^{19}$ ). Some instances are communities focused on specific subjects, such as travel or technology. Others are larger, general-purpose platforms.

There is (deliberately) only partial connection between instances with different policies on certain types of content, such as hate speech. Each instance has its own content moderation process. Many users also choose to feed their toots to their account on the main Twitter platform.

\footnotetext{
17 Source: Mastodon.

18 The combination of all these federated systems is often referred to as the "fediverse".

${ }^{19}$ Framasoft, PeerTube: A free software to take back control of your videos, undated. See statistics on the "Fediverse" at https://the-federation.info
} 


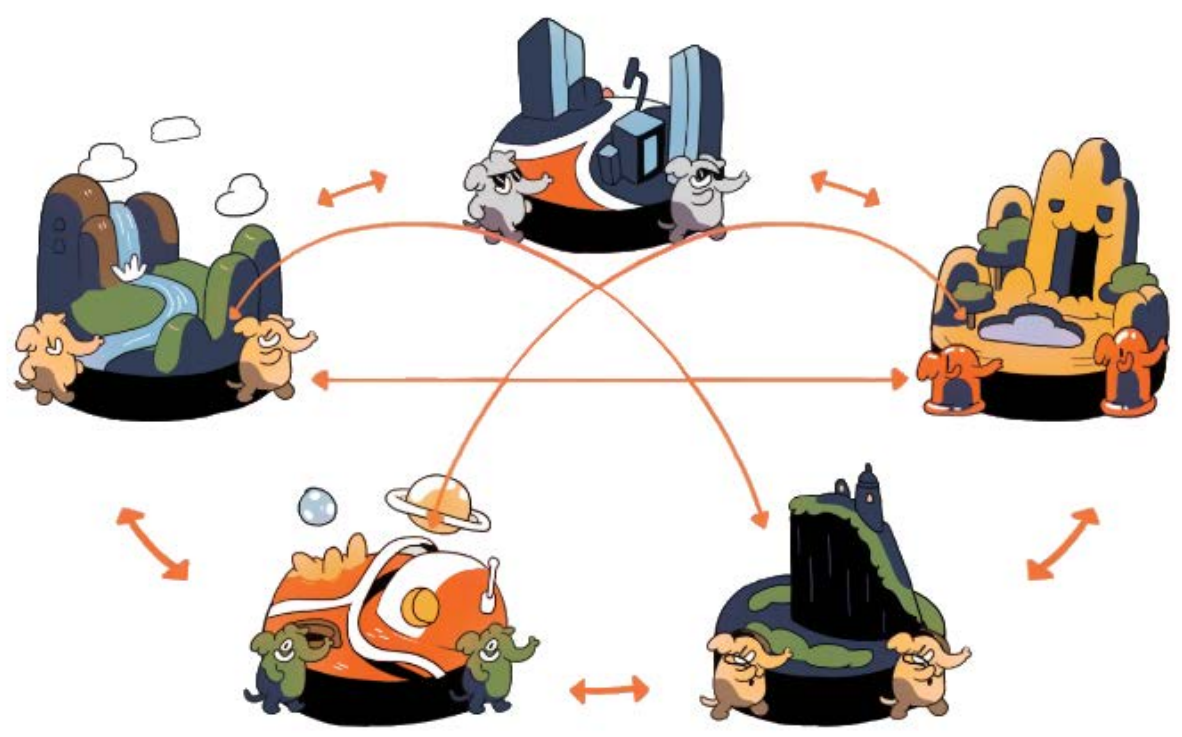

Figure 5 Mastodon users can communicate via 500-character "toots" with other users on their own "instance", and on other connected instances and services

The Mastodon software development, and one of the most popular instances, is supported via an ongoing crowd-funding campaign.

Facebook announced in 2019 it was merging the infrastructure for its Messenger, WhatsApp and Instagram direct messaging services, and potentially standardising on an encrypted messaging protocol first developed by Whisper Systems, for secure messaging app Signal. ${ }^{20}$ This has led to concerns the firm is "scrambling the eggs" to make it more difficult for a competition regulator in future to order a functional (or even structural) separation of the services, as explained by Nobel laureate Jean Tirole. $^{21}$

Facebook also has extensive capabilities for third party developers to run apps on its own platform, accessing information and contacts (the "social graph" of friends) when authorised by its users, and thereby extending its own capabilities. Figure $6^{22}$

\footnotetext{
${ }^{20}$ LH Newman, The Pitfalls of Facebook Merging Messenger, Instagram, and WhatsApp Chats, Wired, 25 January 2019.

$21 \mathrm{~J}$ Tirole, Competition and the Industrial Challenge for the Digital Age, Institute for Fiscal Studies "Inequalities in the Twenty-First Century" review background paper, 3 April 2020, p.26.

${ }^{22}$ Source: CMA, fn 5, p.W12.
} 
shows the CMA mapping of the ability of users of other platforms to "cross-post" content to and from Facebook.

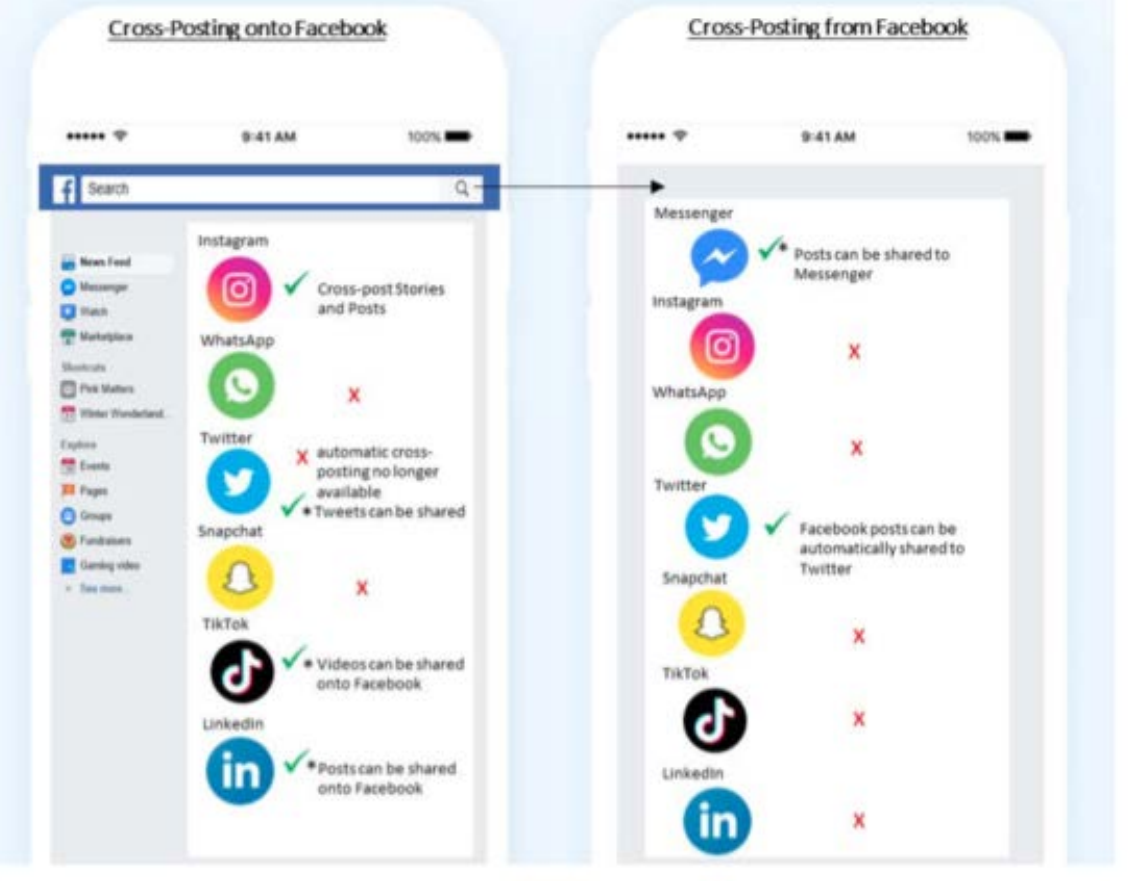

Figure 6 Users of other platforms' ability to post to/from Facebook

Facebook has reduced or blocked access to some of these capabilities since 2010, including stopping Twitter's Facebook app finding other friends using the service; stopping Instagram photos appearing on Twitter; then in 2013 cutting off apps "including Vine, Yandex Wonder, Voxer and more." ${ }^{23}$ As Tirole recently noted:

As for Facebook, (limited) data portability already exists, enabling the possibility of an individual's migration toward another social network. "Social graph APIs" would further allow users to invite their friends to join the new platform and multi-home; cross-posting ability would allow a user to stay on multiple social networks at low cost. As was the case for telecommunications or open banking standards, such interoperability standards probably could only be set by governments or neutral not-for-profit bodies. ${ }^{24}$

\footnotetext{
${ }^{23}$ B Thompson, Portability and Interoperability, Stratechery, 3 December 2019.

24 Tirole, fn 21, p.16.
} 
Facebook's terms and conditions until 2018 included a "non-replication" principle to limit the ability of other tools to provide functionality competing with Facebook's own services - as does Twitter's terms and conditions. ${ }^{25}$

\section{High levels of concentration in digital platforms}

For many large online platform services, one or two ${ }^{26}$ companies already have an extraordinarily high share of national markets. The Furman review estimated this in the UK at close to $100 \%$ for mobile operating systems and online search, with social media above $90 \%$, shown in Figure 7: ${ }^{27}$

\section{Chart 1.B: Combined indicative market shares of current leading two companies in selected UK digital markets}

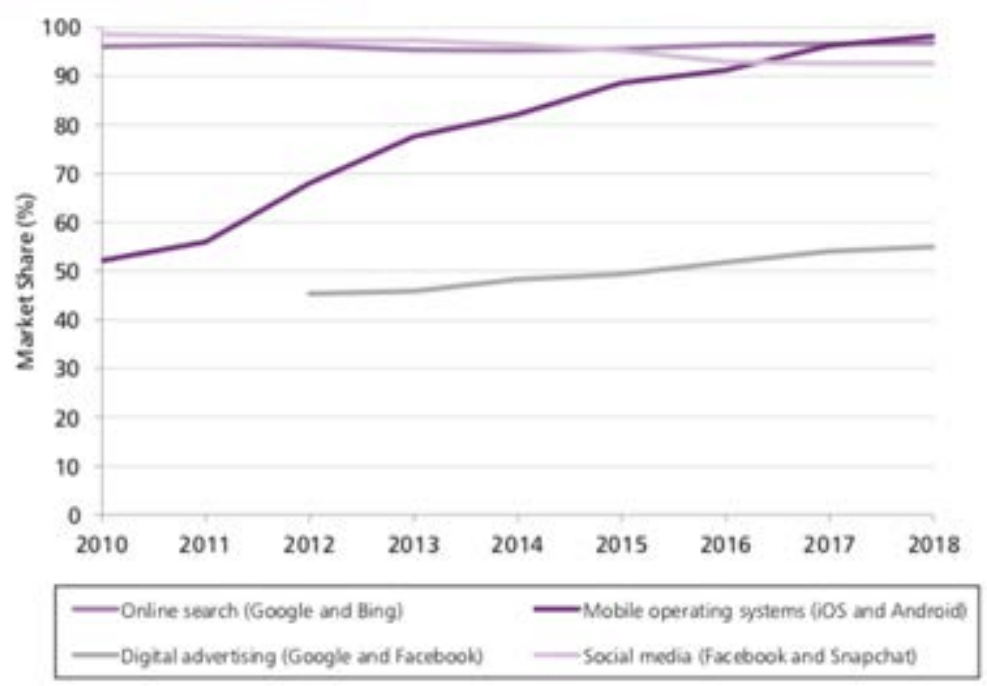

\footnotetext{
${ }^{25}$ CMA, fn 5, Appendix W, p.2.

${ }^{26}$ One former official interviewee reported: "Showing collective dominance is very hard under TFEU $\S 102$ because of the Airtours merger decision so it's never done; tacit collusion (I'm thinking what you're thinking) is not caught by §101. So the combination means nothing gets done." Cave et al. note: "a translation to oligopoly presents different challenges than a transition to competition, and a debate has been raging over whether the [telecoms regulatory] framework is robust enough to deal with the challenge of 'small numbers' markets. One form of potential abuse might be 'collective' dominance (also known as tacit collusion). Ultimately, the sector has considerable barriers to entry and only a handful of players repeatedly interacting with one another. But many regulators believe that showing this form of dominance under the regulatory framework has been rendered almost impossible by the demands that have been placed upon its demonstration by judgments of the European Court. Alternatively, there might be several firms that each exercise single-firm dominance: possibly by exploiting locked-in customers who are disengaged or are baffled by the difficulties that are placed in their way when they seek to 'search and switch' in bundled markets." (p.54)

27 Source: Furman et al., Unlocking Digital Competition (2019), p.25
} 
Figure 7 Combined indicative market shares of current leading two companies in selected UK digital markets

Since Internet users' attention is overall a fixed resource (even in pandemic lockdown, there are limited waking hours), and critical for the advertising-funded services that make up most Internet usage, platforms that can gain the highest percentages of attention are at a significant advantage. The CMA found Google and Facebook's joint share of online user attention in the UK in April 2020 was $39 \% .{ }^{28}$

The European Parliament's 2019 competition report "notes with regret that one search engine that has over $92 \%$ of market share in the online search market in most of the Member States has become a gatekeeper of the Internet". ${ }^{29}$ Research company SensorTower found in May 2020 Facebook owned four of the top ten downloaded (non-game) apps worldwide (WhatsApp, Facebook, Messenger and Instagram), while Alphabet owned two (Google Meet and YouTube). ${ }^{30}$

The CMA estimated:

search advertising revenues totalled around $£ 7.3$ billion in 2019 , of which more than $90 \%$ was earned by Google. Total spend on display advertising was worth $£ 5.5$ billion, of which we estimate more than half went to Facebook. Overall, we estimate that around $80 \%$ of all expenditure on search and display advertising in the UK in 2019 went to Google or Facebook... These issues matter to consumers: if competition in search and social media is not working well, this canlead to reduced innovation and choice, while poor competition in digital advertising can increase the prices of goods and services across the economy, and undermine the ability of newspapers and other providers who rely on digital advertising revenue to produce valuable content ${ }^{31}$ (shown in Figure $8^{32}$ ).

\footnotetext{
${ }^{28}$ CMA, fn 5, p.48.

${ }^{29}$ European Parliament Committee on Economic and Monetary Affairs, Report on competition policyannual report 2019 (2019/2131(INI)), 25 February 2020, §40.

30 SensorTower, Top Apps Worldwide for May 2020 by Downloads, 2 June 2020.

${ }^{31}$ CMA, fn 5, p.42.

${ }^{32}$ Source: CMA, fn 5, p.309
} 


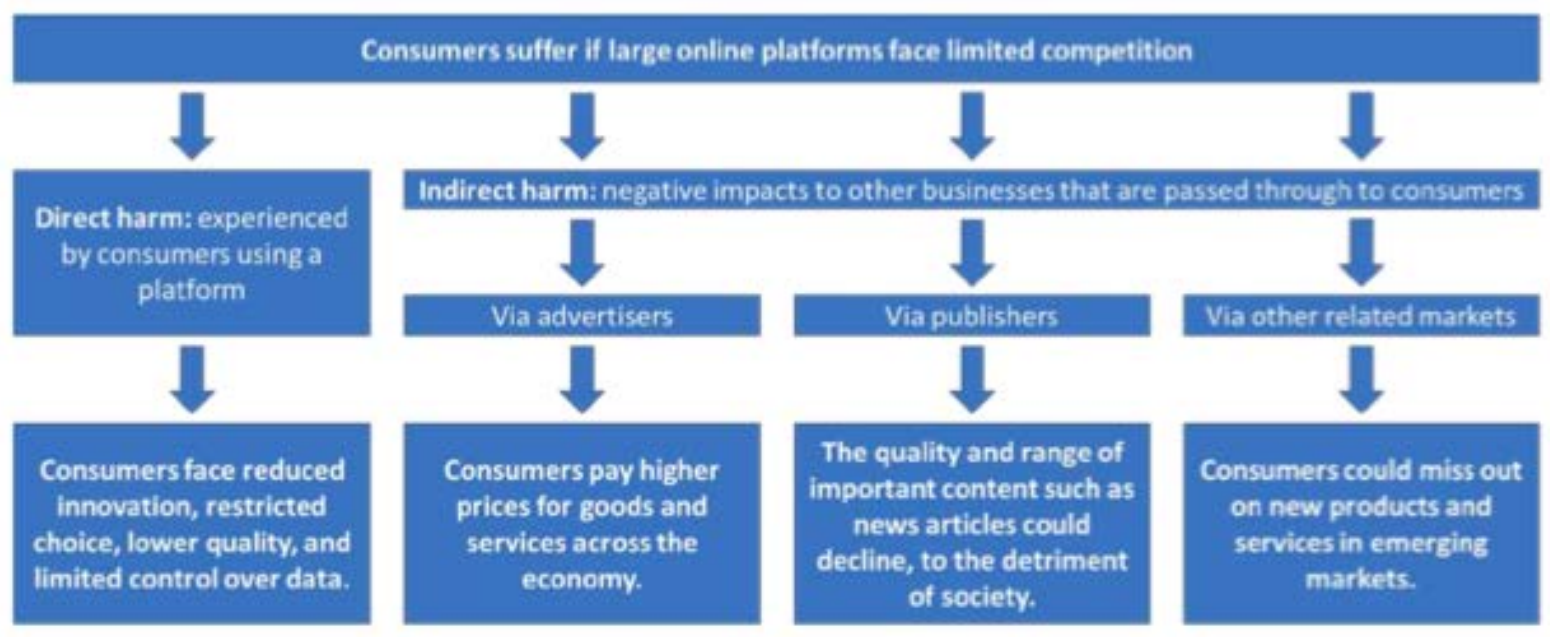

Figure 8 CMA simplified assessment of consumer harm

An additional competition concern is that dominant firms are able to enter new, related ("adjacent") markets at a great advantage to competitors, using their knowledge of customers in one or more markets they already dominate; and use customer information from those new markets to support their existing dominant position. Hence "a first mover in market A can leverage its dominant position, which comes with an advantage on user information, to let connected market B tip, too, even if market $B$ is already served by traditional incumbent firms." ${ }^{33}$

The UK's Competition and Markets Authority found in 2020: "Facebook has significant market power in social media. Strong network effects mean that entry over the last decade has only been successful where platforms have provided a sufficiently different service, that does not compete closely with Facebook. By controlling (and sometimes degrading) the level of interoperability that it offers to other social platforms, Facebook has further insulated itself from competitive pressure." ${ }^{44}$

\section{Economic impacts of interoperability}

The EU and many other jurisdictions have extensive, well-developed competition law frameworks, ${ }^{35}$ including specialised legislation for electronic communications

\footnotetext{
${ }^{33}$ GR Barker and M Cave, Predicting and Forestalling Market Tipping: The Case of Ride-Hailing Apps in the UK, SSRN working paper, 17 January 2020, p.9.

${ }^{34}$ CMA, fn 5, p.73.

35 Treaty on the Functioning of the European Union, Title VII, Chapter 1, Section 1, OJ C 326, 26.10.2012, p. 47; Council Regulation (EC) No 1/2003 of 16 December 2002 on the implementation of the rules on competition laid down in Articles 81 and 82 of the Treaty, OJ L 1, 4.1.2003, p.1.
} 
networks and services. ${ }^{36}$ Why should large digital platforms need further, special rules?

Economists have found these platforms often benefit from "extreme returns to scale and scope". Since platform costs are mainly fixed, such as developing software, and building relationships with suppliers and other types of customers such as advertisers (so-called "n-sided markets"), they can support millions of additional users at low additional cost-per-user, and encourage users of one service to try a related service, making use of already-gathered data. ${ }^{37}$ These additional users can generate further revenues and investment, which can improve the quality of service further $^{38}$ - while smaller competitors face more expensive finance and customer acquisition costs, especially for intangible investments with limited collateral. ${ }^{39}$

Many platforms benefit from strong "network effects", where each new user makes the service more valuable for all existing users (since, for example, they can message or share a photo with an additional person; additional videos can be used to train more accurate object recognition algorithms for all users; or a larger customer base encourages more apps to be developed). And it may be difficult for users to switch to, or even try out, competing services, if doing so requires significant quantities of user data to be transferred ${ }^{40}$ - even though the General Data Protection Regulation (2016/679/EU) $§ 20$ (so-called "data portability") gives European users the right to do this, for some types of personal data (volunteered and observed data processed with user consent or for the performance of a contract ${ }^{41}$ ). As Carl Shapiro and (Google's chief economist) Hal Varian put it:

Worse yet for would-be entrants and innovators, switching costs work in a non-linear way: convincing ten people connected in a network to switch to your incompatible network is more than ten times as hard as getting one customer to switch. But you need all ten, or most of them: no one will want to be the first to give up the network externalities and risk being stranded. Precisely because various users find it so difficult to coordinate to switch to an

\footnotetext{
${ }^{36}$ Directive 2002/21/EC of the European Parliament and of the Council of 7 March 2002 on a common regulatory framework for electronic communications networks and services, OJ L 108, 24.4.2002, p.33.

${ }^{37}$ Crémer et al., fn 3, p.19.

38 OECD, Big data: bringing competition policy to the digital era (Paris: OECD, 2016).

${ }^{39}$ Furman et al., fn 4, pp.32-38.

${ }^{40}$ Crémer et al., fn 3; Furman et al., pp.32-38.

${ }^{41}$ Article 29 Working Party, Guidelines on the right to data portability, endorsed by the European Data Protection Board on 25 May 2019, pp.8-10.
} 
incompatible technology, control over a large installed base of users can be the greatest asset you can have. ${ }^{42}$

These obstacles make it difficult for startups and larger firms to break into such markets, competing "on the merits", even with innovative products, large investments, and access to extremely skilled technologists - as Google found when it was unable to succeed with social media services Google+, Wave or Buzz; ${ }^{43}$ and as Microsoft found with a Windows-based operating system for smartphones, and even in making significant inroads with its Bing search engine. ${ }^{44}$ The UK CMA found:

Google+'s failure:

- demonstrates that access to a wide base of potential users and consumer data, as held by Google, is not determinative of successful entry to the social media sector; and

- indicates that entry with a service similar to that provided by Facebook is very difficult indeed. ${ }^{45}$

\section{Multi-homing and tipping}

When users make use of more than one platform providing a similar service - at least a "partial substitute" - they are said to be "multi-homing". This is common with instant messaging, and to some degree with social media. ${ }^{46}$ But for ride-hailing platforms (such as Uber and Lyft), 2017 US data showed "most riders single home or are loyal to their favourite brand-or simply creatures of habit." 47 The CMA also found:

consumers' use of multiple [social media] platforms does not necessarily imply that their services can be used as substitutes by consumers and that these other platforms can meet the same consumer needs as Facebook... The high proportions of other platforms' audiences that cross-visit with Facebook, and the significantly lower proportion of Facebook's audience that

\footnotetext{
${ }^{42}$ C Shapiro and HR Varian, Information Rules: A Strategic Guide to the Network Economy (Boston: Harvard Business School Press, 1999) pp. 184-5.

${ }^{43}$ One interviewee suggested this was "because it was competing with a platform, not a 'traditional incumbent', and therefore could not benefit from the "first-mover advantage", which in fact played against Google." See also LL Gormsen and JT LLanos, Facebook's Anticompetitive Lean in Strategies, SSRN Working Paper, p.19.

44 "In April 2020, online search engine Bing accounted for 6.25 percent of the global search market, while market leader Google had a market share of 86.02 percent. Chinese search engine Baidu's market share was 0.83 percent." Source: Statista, Global market share of search engines 2010-2020.

${ }^{45}$ CMA, fn 5, p.138.

${ }^{46}$ CMA, fn 5, p.129.

47 Barker and Cave, fn 33, p.13.
} 
cross-visits with each of the other platforms, suggest that Facebook is a must-have platform. Cross-visiting statistics show that other platforms are used by sub-sets of users, but nearly always in combination with Facebook. ${ }^{48}$

A related competition concern is "tipping", the point at which one firm takes most of a market

driven by a combination of economies of scale and scope; network externalities whether on the side of the consumer or seller; integration of products, services and hardware; behavioural limitations on the part of consumers for whom defaults and prominence are very important; difficulty in raising capital; and the importance of brands. ${ }^{49}$

Multi-sided markets (where a platform intermediates between multiple sets of users, such as taxidrivers and passengers, or social media users and advertisers, or restaurants, customers, and delivery drivers; with indirect network effects between the multiple sides of the market internalised by the platform) are more likely to tip when fewer users on one or more sides multi-home. ${ }^{50}$

Advertising-funded platforms use current users to attract additional users and advertisers, ${ }^{51}$ which makes it particularly difficult for new services to compete with "free" large existing platforms. Competitors find it difficult to attract users to a new paid-for service - but also difficult to attract advertisers to a small new platform. ${ }^{52}$

One possible route to doing so is for a competitor to offer complementary services, so long as users can easily use several platforms simultaneously (i.e. are multi-homing), and then grow over time to compete directly. ${ }^{53}$ However, the CMA noted: "entering by providing consumers with a specialised service may limit the scale of the consumer base that new entrants can develop in the long-term and may also result in consumers developing networks of connections on the platform specific to a particular need." ${ }^{54}$ Sciliani and Giovannetti add:

This is the typical disruptive innovation scenario whereby the new entrant does not initially develop a fully-fledged offer, but instead focuses on a narrow scope with the strategy to broaden it as the customer base grows. Under

\footnotetext{
${ }^{48}$ CMA, fn 5, p.129.

${ }^{49}$ Furman et al., fn 4, p.4.

50 Barker and Cave, fn 33, p.12.

${ }^{51}$ While some economists argue "gatekeeper" platforms are by definition two or more-sided markets, others argue that a large user base can still give a one-sided platform gatekeeping power.

${ }^{52}$ Crémer et al., fn 3, p.20.

${ }^{53}$ Crémer et al., fn 3, pp.30, 36-37.

${ }^{54}$ CMA, fn 5, p.135.
} 
these circumstances, users may be reliant on the incumbent platforms for other (complementary) services not offered by the new entrant to a different degree. Therefore, users choosing an entrant providing only a smaller range of services from the incumbent platform would tend to have a higher propensity to switch. ${ }^{55}$

Multi-homing is not cost-free to users. They must spend time and resources to install multiple apps, read privacy policies and other terms of use (and often consent to various types of monitoring), create accounts, manage passwords, and learn features. Mistakes can be embarrassing and/or costly in communications with colleagues and friends. An infamous UK example is former shadow chancellor Ed Balls mistakenly tweeting his name, which was retweeted tens of thousands of times, and has since become the basis for an annual "\#EdBallsDay". ${ }^{56}$ As Zoom became popular during the Covid-19 pandemic in early 2020 with 3,000\% growth from a low base, ${ }^{57}$ there were numerous cases of "zoom-bombing", where intruders took advantage of security misconfigurations to share offensive and sometimes illegal content with call participants. ${ }^{58}$

\section{Gatekeepers, conglomerates and ecosystems}

Three further terms are useful in differentiating large online platforms:

Gatekeeper platforms are able to control access between businesses and potential customers, for example advertisers wishing to reach users of a ubiquitous social media platform, retailers selling to the customers of an extremely popular e-commerce platform, or messaging apps wishing to connect to very large user bases on dominant services (such as the forthcoming integrated Facebook/WhatsApp/Instagram messaging service, with Facebook already seeing 2.99bn users of these collective services in the first quarter of $2020 .{ }^{59}$ ) Such platforms are thereby able to control access and charge high fees; manipulate rankings or prominence; and control reputations of firms. ${ }^{60}$

\footnotetext{
${ }^{55}$ P Siciliani and E Giovannetti, Platform competition and incumbency advantage under heterogeneous switching cost - exploring the impact of data portability, Bank of England Staff Working Paper No. 839, December 2019, p.5.

${ }^{56}$ E Lawford, Happy Ed Balls Day 2020! Here's why social media users mark April 28 with the ex-politician's name, Evening Standard, 28 April 2020.

57 Ofcom, Online Nations (London: Office for Communications, 2020).

${ }^{58} \mathrm{~K}$ Paul, Zoom releases security updates in response to 'Zoom-bombings', The Guardian, 23 April 2020.

${ }^{59}$ Facebook, Inc., Facebook Reports First Quarter 2020 Results, 29 April 2020.

${ }^{60}$ Furman et al, fn 4, p.42.
} 


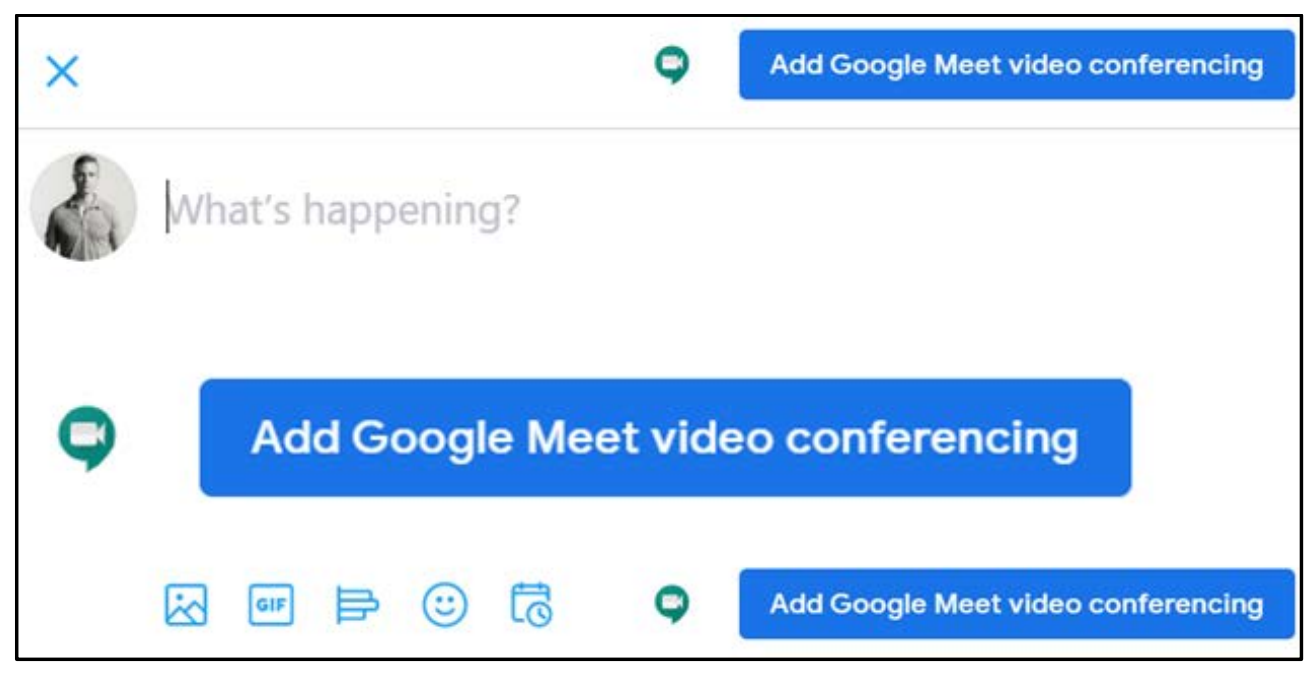

Figure 9 Andrew Reed's humorous suggestion for a Twitter redesign, inspired by Google's multiple user interface interventions to promote its videoconferencing service

Conglomerates are companies with a broad range of sometimes weakly-related businesses, achieved through growth, startup financing, and acquisitions. Bourreau and de Streel give the examples of Amazon (moving from book sales, to a wide range of products, to "payment services, cloud computing, as well as movie and television series production and distribution"), Google ("from search to maps, operating systems, mobile and personal computing devices, and cloud services", shown humorously in Figure $7^{61}$ ) and Facebook (from basic social media to "photo and video social networking with Instagram, messaging with WhatsApp, and virtual reality with Oculus VR."). ${ }^{62}$

Ecosystems are collections of services (such as Apple's iPhone, iOS, App Store, and Apple Pay), connected via privileged channels not fully available to competitors. ${ }^{63}$ (NB: the tech industry and media use the term more broadly, including other companies' products and services.) The UK Competition and Markets Authority visualised the Google and Facebook ecosystems in 2020 as shown in Figure 10: ${ }^{64}$

\footnotetext{
61 Source: @andrew_reed/Twitter, 9 July 2020.

${ }^{62} \mathrm{M}$ Bourreau and A de Streel, Digital Conglomerates and EU Competition Policy, March 2019.

${ }^{63}$ Crémer et al., fn 3, p.34.

${ }^{64}$ Source: CMA, fn 5, p.57.
} 

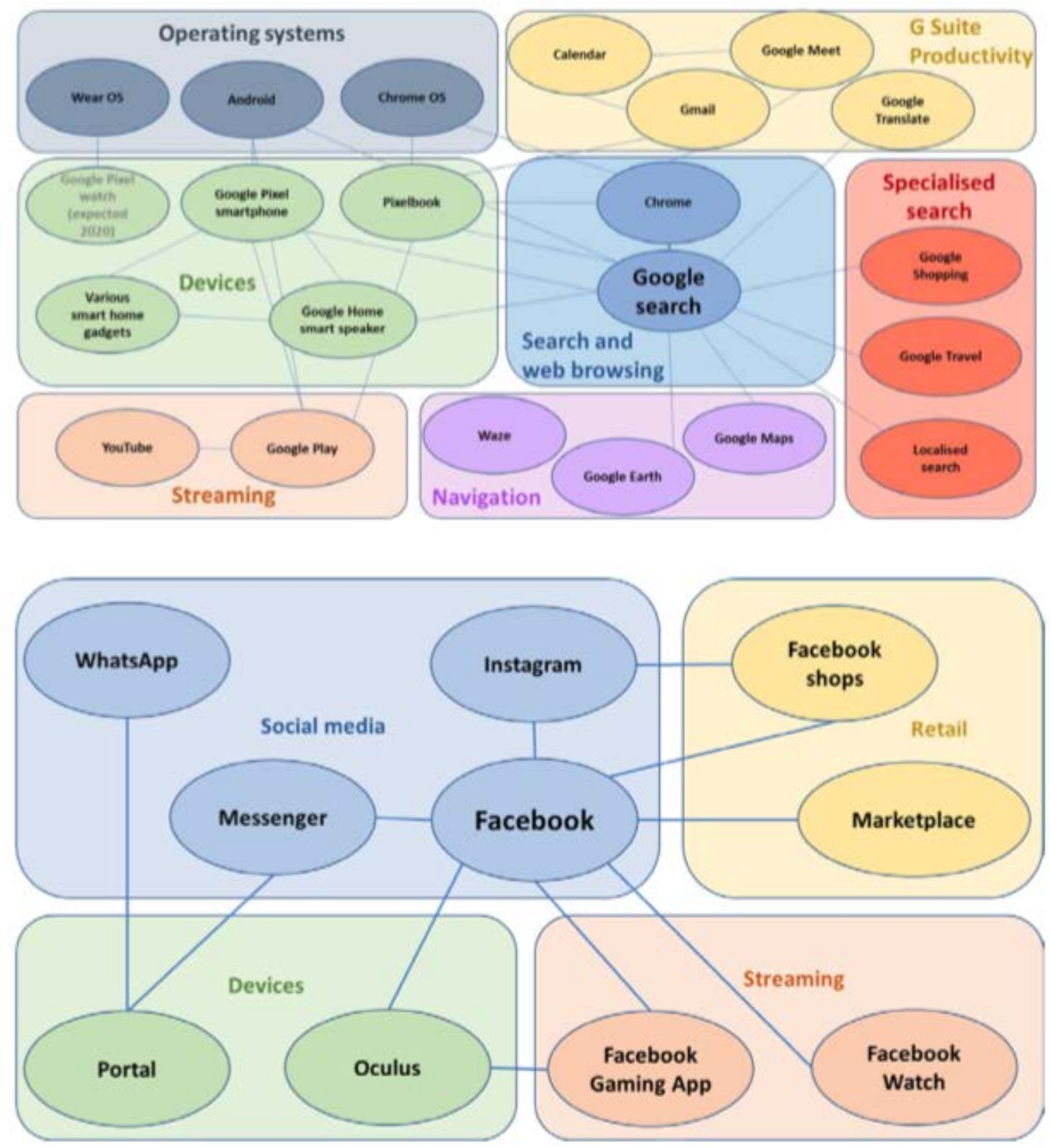

Figure 10 CMA interpretation of a selection of Google and Facebook services

The CMA noted ecosystems in a market can affect "[p]rice, quality and choice in adjacent markets - a powerful platform can leverage its strong position in its core market into other adjacent markets, ultimately giving itself an advantage over its rivals. The effects of limited competition for consumers discussed above are then potentially spread out to a wider range of markets. Importantly, this could act as a handbrake on innovation right across the ecosystem of online services and related 
technology." ${ }^{55}$ The CMA found specifically: "Google and Facebook have increasingly expanded from general search and social media respectively into related markets. This can provide benefits for consumers, for example by increasing choice, or allowing them to access services with less friction. However, we are concerned that Google and Facebook can leverage their market power into adjacent markets in a way that further excludes rivals, diminishing competition and reducing choice and innovation over time." 66

\section{Complementary innovation and homogenisation}

As a mature and diversified business, Microsoft has a much wider range of products and services than some of its Silicon Valley competitors. ${ }^{67}$ Many of these are complements to other firms' services - to a significant extent, due to US and EU competition enforcement actions during the 1990s and 2000s - and hence the company has a stronger incentive to support interoperability.

Such firms have incentives to interoperate with market leaders and other competitors, as can be seen with three recent examples relating to Microsoft, and to form strategic alliances that match their own longer-term business plans: ${ }^{68}$

- Microsoft worked with the producer of Apple's device management software to let its cloud Active Directory authentication work with Macs (a complementary service, since Microsoft's cloud services compete in much broader markets than Apple's cloud services, which are focused on its own users).

- Google and Microsoft improved compatibility between Google Calendar and Microsoft Exchange, enabling users of both to take advantage of network effects across the joint platforms. The companies compete on online office productivity software, with 55.2\% (Google Apps) and 38.06\% (Office 365) of the global market from 2015-2020 according to Statista. This is close to a position of joint dominance.

- Microsoft enabled its speech assistant Cortana to work directly with Amazon's Alexa (complements in adjacent markets), so users of either can access largely complementary services on both platforms, including Office 365.

Where one firm has a dominant position in a market with strong network effects, it will have strong disincentives to allow interoperability. A regulatory requirement for interoperability in such cases would allow competitors to connect new services to

${ }^{65}$ CMA, fn 5, p.71.

${ }^{66} \mathrm{CMA}$, fn 5, p.73.

67 O Wallach, How Big Tech Makes Their Billions, Visual Capitalist, 6 July 2020.

${ }^{68}$ A Hickey, Why Microsoft is pushing for interoperability with its competitors, ClO Dive, 25 Oct. 2017. 
an existing user base (for example, in the first quarter of 2020, 2.99 billion monthly users of Facebook, Instagram and WhatsApp ${ }^{69}$ ), connect users across those services, and benefit from the resulting network effects. As Mastodon's developer Eugen Rochko commented:

8 years ago, everyone had 20 social media profiles without batting an eye, but nowadays people are legitimately hesitant to use just one more platform in addition to Twitter and Instagram... ${ }^{70}$ It's one thing to get someone to try out Mastodon, but for them to keep using it, they need to acquire the happy medium of content and personal connections to have a reason to come back... features actually play a much lesser role than you would think. People would use a social network based on smoke signals if everybody else was using it. ${ }^{7}$

Interoperability can further benefit consumers through enabling combinations of component products/services that best meet their needs, and increasing innovation/reducing prices in complementary goods, as well as reducing obstacles to switching providers (two examples of complementary services to Twitter are shown in Figure 11, connecting via its API).

\footnotetext{
${ }^{69}$ Facebook, Inc. fn 59.

70 See also P Ohm (2008) The Myth of the Superuser: Fear, Risk, and Harm Online, UC Davis Law Review Vol. 41, No. 4, p. 1327.

${ }^{71} \mathrm{~S}$ Tilley, One Mammoth of a Job: An Interview with Eugen Rochko of Mastodon, Medium, 9 July 2018.
} 


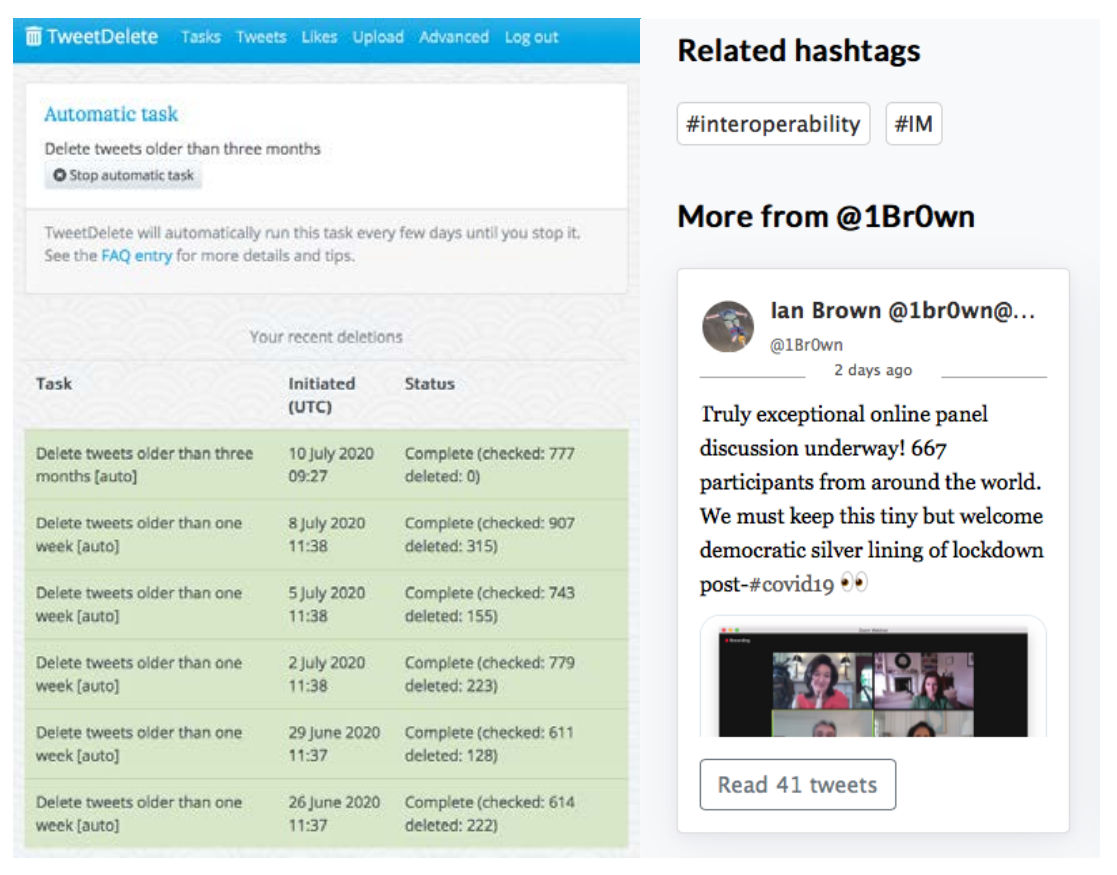

Figure 11 TweetDelete and Thread Reader, two complementary services to Twitter

However, interoperability can also lead to competing products to settle around a standard set of features, reducing incentives for innovation. The creator of the widely-used secure messaging app Signal has commented at length on the difficulties federated systems face in adding new features and upgrades (such as end-toend encryption.) ${ }^{72}$ In its recommendation of interoperability requirements for social media, the CMA commented:

stakeholders have raised concerns about the impact of standardisation on incentives to innovate. However, whilst this intervention may require certain features to be standardised, the specific features we have under consideration, such as words, pictures and videos, are not recently innovative and as such an intervention is unlikely to diminish incentives to innovate. Indeed, the ability to reach a wider audience should improve incentives to invest and innovate in additional services to attract new users. ${ }^{73}$

\section{Static vs dynamic effects}

Competition economists often contrast short term (or static) and longer-term (or dynamic) competition. Static competition is less significant in markets featuring

\footnotetext{
${ }^{72}$ M Marlinspike, Reflections: The ecosystem is moving, 10 May 2016.

${ }^{73}$ CMA, fn 5, Appendix W p.13.
} 
significant innovation, such as online platforms, since its results can be "[f]irms never overcharge customers, but firms offer customers no exciting new products." ${ }^{174}$

Dynamic competition occurs as product and process innovation takes place. Schumpeter, still one of the most-cited economists on innovation, described it in 1943: "competition from the new commodity, the new technology, the new source of supply, the new type of organization-competition which commands a decisive cost or quality advantage and which strikes not at the margins of the profits and the output of existing firms, but at their foundations and their very lives. ${ }^{\prime 75}$

In the short run, a smaller number of larger companies often benefit from scale efficiencies and network effects. This will benefit consumers if those efficiencies result in lower prices or higher quality - but that in turn is less likely with lower levels of competition.

As the CMA illustrated, "[t]he potential user benefits of interoperability are illustrated by Facebook's decision to develop an interoperable solution across its messaging services: Facebook Messenger, Instagram's Direct Messenger and WhatsApp. Whilst this type of integration can give rise to competition concerns, particularly when applied asymmetrically as it could strengthen Facebook's market position, it also illustrates the efficiency benefits that can arise from enhanced interoperability." ${ }^{76}$

Increased competition on (within) the market in question (e.g. social media) encourages new competitors to enter, tending to reduce prices. But with large economies of scale and network effects, there will likely be only a small number of platforms competing to provide the same type of service. ${ }^{77}$

In the long run, dynamic competition leads to increased quality and innovation. For online platforms, this is more likely to come from competition for the market, where an incumbent is pushed aside by a competitor. A market can remain "contestable" even with very few firms, if other potential competitors can still enter the market. Some economists have claimed previous technology market transitions demonstrate this effect, from IBM's PC hardware dominance, to Microsoft's MS-DOS and Windows dominance, to Netscape's browser early successes, to Apple and Alphabet's iOS and Android smartphone OS joint dominance. But as the UK Furman review observed:

\footnotetext{
74 JG Sidak \& DJ Teece (2009) Dynamic competition in antitrust law, Journal of Competition Law \& Economics, 5(4), p. 603.

75 J Schumpeter, Capitalism, Socialism \& Democracy (London: Routledge, 6th ed., 2006), p.84.

${ }^{76} \mathrm{CMA}$, fn 5, Appendix W p.3.

${ }^{77}$ Crémer et al., fn 3, p.36.
} 
these changes were facilitated, in part, by government policy - in particular antitrust cases against these companies, without which the changes may never have happened. Today, network effects and returns to scale of data appear to be even more entrenched and the market seems to have stabilised quickly compared to the much larger degree of churn in the early days of the World Wide Web. ${ }^{78}$

More generally, this "controversial" theory of market "contestability" "is even more doubtful in the presence of network externalities and ecosystems", since a competitor must "convince users of the incumbent to coordinate their migration to its own services" (often in the presence of significant switching costs), and "the lack of interoperability with other services of the same ecosystem and the absence or limited access to historical and future ecosystem data will make it difficult for a new entrant to compete on the merit of the specific service and/or algorithm." 79 Tirole adds: "Firms might be playing dirty tricks in the marketplace, spend money on killer acquisitions or hire battalions of lobbyists and lawyers to acquire or preserve their dominant position. Contestability does not rule out social waste." 80

The CMA concluded:

We see from analysis of Google's and Facebook's profitability that, even considering a relatively static snapshot of the world as it is today, the potential gains for consumers from increased competition are substantial... Looking to the future, we could expect the dynamic benefits to consumers from a more competitive market to be far greater than the static gains, as the real prize for consumers over the long term will come from increased innovation and the new transformative products and services that will come online as a result. ${ }^{81}$

\section{Social impacts of interoperability}

While much of the EU policy debate relating to interoperability takes place in narrow competition economics terms, it could have a much broader impact on European societies. ${ }^{82}$

Many competition economists argue that competition policy and interventions should be concerned only with narrow economic measures - in the prevailing US

\footnotetext{
${ }^{78}$ Furman et al., fn 4, p.4.

${ }^{79}$ Crémer et al., fn 3, p.36.

80 Tirole, fn 21, p.3.

${ }^{81}$ CMA, fn 5, p.71.

${ }^{82}$ I Brown and C Marsden, Regulating Code (Cambridge: MIT Press, 2013) pp.183-203.
} 
policy consensus since the 1980s, focused on a narrow "consumer welfare" measure, largely around price (which has obvious issues when so many online platform services are provided "free"). ${ }^{83}$ Alongside price, the EU competition framework pays greater attention to quality, choice and innovation.

Even in the EU, however, there are obvious important impacts of online platform market structures in areas of policy far from straightforward economic concerns. For example, as Graef, Clifford and Valcke note:

Rather than a substantive benchmark, fairness can be regarded as an inherent objective or outcome of competition enforcement. By intervening against anticompetitive practices, EU competition law protects the competitive process in the internal market to the benefit of consumers, competitors, and the economy as a whole. In this manner, competition enforcement thus contributes to a fairer society. Fairness can also be regarded as constituting part of the notion of 'competition on the merits' that is used to distinguish 'normal' competitive behaviour on the basis of price, quantity, quality, choice, and innovation from conduct that restricts competition. In this sense, when markets work fairly, businesses compete on the merits. ${ }^{84}$

As the UK's Competition and Markets Authority added in July 2020, "competition concerns can also lead to and exacerbate a range of broader online harms... For example, a thriving and competitive market for independent news and journalism is essential for an effective democracy: if the sustainability of authoritative journalism is undermined, this is likely to worsen concerns around fake news and misleading information. More generally, if users are to be truly empowered to keep themselves and their children safe online, adequate choice over platforms and other digital providers is indispensable." 85 And there are concerns that business models based around maximising user attention (and hence advertising revenues) have negative side effects, including issues such as the amplification of disinformation, hate speech and extremism. ${ }^{86}$ Interoperability could help build the "counter powers", and disperse opinion-forming power, identified as important by Helberger. ${ }^{87}$

\footnotetext{
${ }^{83}$ M Stucke and A Ezrachi, Competition Overdose (New York: HarperCollins, 2020).

${ }^{84}$ Graef et al., fn 11, p.205.

${ }^{85}$ CMA, fn 5, p.71.

${ }^{86}$ C Marsden, T Mayer and I Brown (2020) Platform values and democratic elections: How can the law regulate digital disinformation? Computer Law \& Security Review, Vol. 36, 105373.

87 N Helberger, (2020) The Political Power of Platforms: How Current Attempts to Regulate Misinformation Amplify Opinion Power, Digital Journalism, s.5.
} 


\section{Platforms as essential social infrastructure}

In many EU countries, particularly during the Covid-19 pandemic, large online platforms increasingly act as essential "social infrastructure" - used by families to share news and photos; schools to communicate with parents and students, and to teach remotely; sports teams to arrange games; politicians to communicate with constituents; campaign groups to organise protests; and many other aspects of modernday life. As shown in Figure 12, ${ }^{88}$ use of Facebook across the EU in the first quarter of 2020 (largely pre-pandemic) varied from 39\% of the population in Latvia to 88\% in Malta, with an average of $56 \%$.

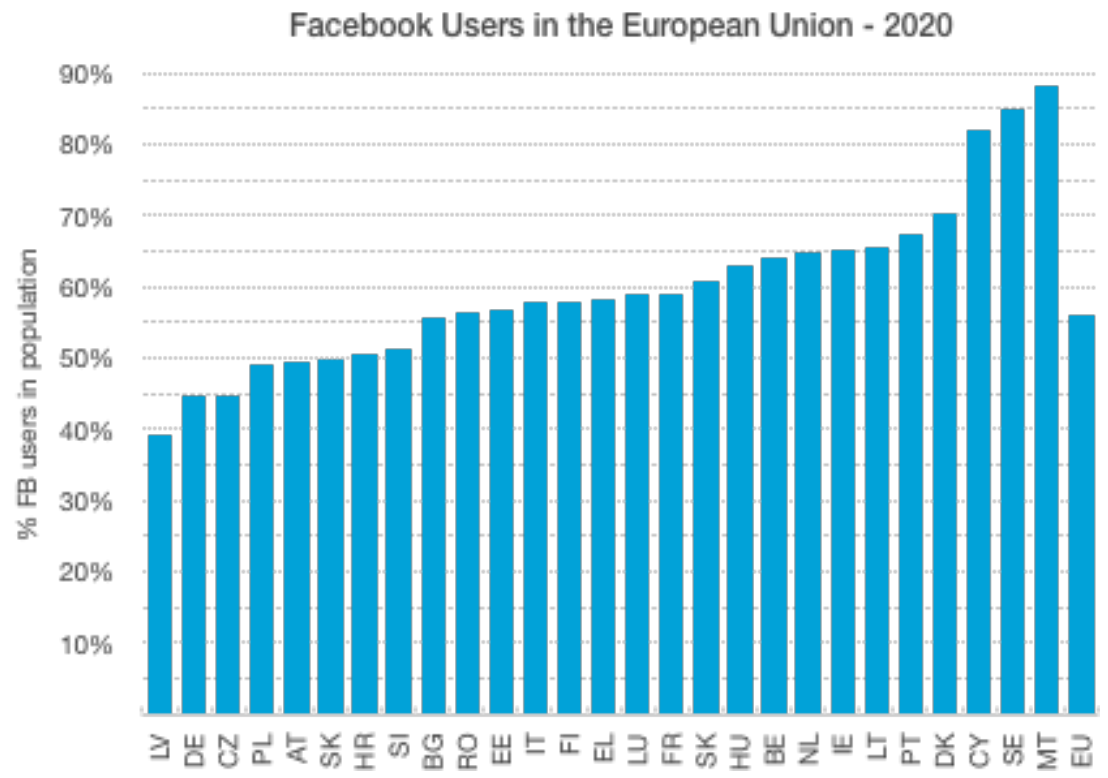

Figure 12 Facebook users in the population of the EU's 27 member states, March 2020

As Facebook's former head of policy for Europe, Richard Allan, put it, the company's "core value proposition is that it allows you [to] communicate with all (or at least a significant group of) your family and friends." ${ }^{89}$ While Facebook has billions more users than its competitors, this strategy means it can strongly differentiate itself from them by blocking their access to its own users.

From the earliest years of social media usage, boyd found evidence of youth communities sorting themselves between different platforms:

\footnotetext{
${ }^{88}$ Data: Internet World Stats.

${ }^{89}$ R Allan, Pub Rules for Platforms, regulate.tech, 29 June 2020.
} 
As Facebook started gaining momentum, some teenagers switched from MySpace to Facebook. Others joined Facebook without having ever been on MySpace. Still others chose to adopt both... Subculturally identified teens appeared more frequently drawn to MySpace while more mainstream teens tended towards Facebook. Teens from less-privileged backgrounds seemed likely to be drawn to MySpace while those headed towards elite universities appeared to be head towards Facebook. Racial and ethnic divisions looked messier, tied strongly to socio-economic factors, but I observed that black and Latino teens appeared to preference MySpace while white and Asian teens seemed to privilege Facebook. ${ }^{90}$

The social importance of connecting all members of society has long been recognised in regulation of telecommunications, with EU national regulators able to impose interconnection (allowing price negotiations) and interoperability duties on network providers ${ }^{91}$ via the Framework Directive (2002/21/EC) and Access Directive (2002/19/EC), and to mandate a universal service, including to disabled users, under the Universal Service Directive (2002/22/EC).

In promoting competition, the EU internal market, and citizens' interests, $\S 5$ of the Access Directive requires national regulators to "encourage and where appropriate ensure, in accordance with the provisions of this Directive, adequate access and interconnection, and the interoperability of services, exercising their responsibility in a way that promotes efficiency, sustainable competition, efficient investment and innovation, and gives the maximum benefit to end-users." There are also detailed requirements for "network neutrality" by Internet access services in the Open Internet Regulation (2015/2120), to "safeguard equal and non-discriminatory treatment of traffic in the provision of internet access services and related end-users' rights" $(§ 1(1))$. Services must "not block, slow down, alter, restrict, interfere with, degrade or discriminate between specific content, applications or services" except for some narrowly limited purposes (§3(3)).

However, some influential economists argue broad interoperability requirements for platforms are not justified. Kerber and Schweitzer concluded:

The extension of horizontal interoperability regulation from physical infrastructures to interpersonal communications services and digital platforms is, however, not at all obvious. The balance of interests differs significantly. Neither the goal to prevent market tipping nor the universal service rationale are relevant across the board when it comes to digital platforms. Universal

\footnotetext{
90 d boyd (2011) White Flight in Networked Publics? How Race and Class Shaped American Teen Engagement with MySpace and Facebook. In Race After the Internet, eds. Lisa Nakamura and Peter A. Chow-White (New York: Routledge) pp.206-212.

${ }^{91}$ W Kerber and H Schweitzer (2017) Interoperability in the digital economy, Marburg Centre for Institutional Economy, Macie Paper Series No. 2017/02, pp.15-16.
} 
services policies strive to ensure a basic service - but not end-to-end connectivity in any possible respect. Interventions into the digital platform operators' freedom to choose between closed and open systems lacks justification where end users typically engage in multi-homing and thereby ensure de facto end-to-end connectivity themselves. Similarly, where multi-homing is common, tipping may not be an issue. Even where tipping may be a concern, the imposition of interoperability duties upon digital platforms may imply a significantly more interventionist regime than the interconnection requirement between physical networks. It is, therefore, important to clearly distinguish between network interconnection and platform interoperability. ${ }^{92}$

There was extensive discussion in the mid-2010s of interconnection of instant messaging services by the European Commission and telecoms regulators, under the provisions of the European Electronic Communications Code (EECC, 2018/1972, which must be implemented by Member States by 20 December 2020). While the provisions of that Code were weakened from the European Commission's original proposal by opposition from some member states, ${ }^{93}$ it will enable national regulators under certain conditions to impose interoperability upon dominant instant messaging platforms (see the scenarios discussion later). The Digital Markets Act will provide a further opportunity to address these issues.

\section{Media pluralism and diversity}

Broadcast, cable and satellite TV and radio distributors are required in many European countries to carry specified channels, ${ }^{94}$ and to give due prominence in electronic programme guides to certain channels, both to widen the distribution of public service broadcast content, and to protect media pluralism and diversity. ${ }^{95}$ But Germany is the only country yet to consider extending pluralism obligations to major online platforms. ${ }^{96}$ As the European Data Protection Supervisor put it: "[Large online platforms] serve as gatekeepers to the internet, able to control the digital public space, and determine through secret, proprietary means what people can and cannot see - whether it is recommended content or products, commercial ads, political messages or news items." ${ }^{97}$ Helberger notes:

\footnotetext{
${ }^{92}$ Kerber and Schweitzer, fn 91, p.18.

${ }^{93}$ Contrast $\S 59$ in the Commission's proposal with the final $§ 61$. Proposal for a Directive of the European Parliament and of the Council establishing the European Electronic Communications Code (Recast), COM/2016/0590 final - 2016/0288 (COD).

${ }^{94} \mathrm{~L}$ Woods, Must Carry/Must Offer obligations on audiovisual services under EU Law, Harbottle \& Lewis Insights, 20 December 2019.

${ }^{95}$ B van der Sloot (2012) Walking a Thin Line: The Regulation of EPGs, JIPITEC Vol. 3, pp.138-147.

${ }^{96}$ Helberger, fn 87.

97 W Wiewiórowski, Sharing is caring? That depends... European Data Protection Supervisor blog, 13 December 2019.
} 
alongside immediate communication power (such as networking, networked and network-making power), social media also has what I call 'systemic opinion power', which is the power to create dependences and influence other players in a democracy. In so doing, these platforms change the very structure and balance of the media market, and thereby directly and permanently impact the pluralistic public sphere. ${ }^{98}$

The US Stigler report concluded that interoperability "may contribute to reducing the gatekeeping power of [dominant] platforms and positively impact the type of information that users consume." ${ }^{\prime 99}$

A 2020 report from Germany's National Academy of Science and Engineering called for a "European digital ecosystem that is democratically accountable to its citizens. A digital ecosystem that observes European values such as transparency, openness and privacy protection, even in its technical design, can create a digital public sphere that offers fair terms of access and use, strengthens the public debate and safeguards the plurality that forms a key part of Europe's identity."

The report identified the importance to this goal of "a technology strategy characterised by modularity, interoperability, openness and transparency that enables continuous development and a diverse range of business models." ${ }^{\prime 100}$

The British Broadcasting Corporation's (BBC) Director of Radio (and former UK Culture Secretary) complained to a UK parliamentary hearing in June 2020 that the BBC had been unable to agree deals with Amazon and Google for their 'smart speakers' to carry BBC coronavirus coverage (while agreeing a deal for Facebook Messenger to carry the "BBC Corona Bot" to provide health information about the pandemic). He asked whether "we are happy about the biggest organisations in the world, big tech companies with their executives essentially [based] in the [United] States, combining a monopoly in people's kitchens and in living rooms," and suggested users should be given a choice of voice assistants in future. ${ }^{101}$

Helberger concluded:

The source of the political power of platforms is their ability to wield opinion power, whether it is that of their users or politicians, or their ability to influence public discourse for their own purposes. Without adequate safeguards,

\footnotetext{
${ }^{98}$ Helberger, fn 87, s.3.

${ }^{99}$ Stigler, fn 6, p.144.

${ }^{100}$ H Kagermann, U Wilhelm (Eds.) European Public Sphere: Towards Digital Sovereignty for Europe (Munich: acatech - National Academy of Science and Engineering, 2020), p.5.

${ }^{101}$ Mark Sweney, Smart speakers risk creating 'big-tech monopoly' in homes, The Guardian, 16 June 2020.
} 
all commitments to neutrality, fairness and non-manipulation are meaningless. The sheer possibility of the abuse of this immense power for one's own political goals is in itself a threat to any functioning democracy. Dispersing concentrations of opinion power and creating countervailing powers is essential to preventing certain social media platforms from becoming quasigovernments of online speech, while also ensuring that they each remain one of many platforms that allow us to engage in public debate. ${ }^{102}$

\section{Privacy and data protection}

Many platform services are provided at the highly attractive price of "free" to users $^{103}$ - paid for, of course, by extensive user profiling and targeting with behavioural advertising. But the structural obstacles to competition for these services can still negatively impact on quality, innovation and choice for users, as well as the opportunity for European start-ups and larger firms to enter these key global markets. As Commissioner Vestager said in 2016:

Because we know that competition gives consumers the power to demand a fair deal. To shop around to find a better price, or a wider choice of products. To seek out better quality, whatever that means to them - whether it's a more reliable car, or a social network that protects their private data better. ${ }^{104}$

The UK's Furman review similarly noted: "it is clear that well-functioning competitive digital markets have the potential to develop new solutions and increased choice for consumers, where privacy and quality of service can be differentiating factors." 105

The European Parliament's annual competition report for 2019 "[d]raws the [European] Commission's attention to acquisitions carried out by foreign monopolies of digital data operators, including health, financial and educational data, and to the privacy risks involved, which extend far beyond the already damaging effects of transactions of this kind on competition" (§33).

Many academic experts and activists have criticised the lack of enforcement of the GDPR since it came into force in May 2018, particularly by the Irish Data Protection Commission, responsible for regulating many of the Internet giants' European establishments in Dublin. One standards body expert interviewee noted:

\footnotetext{
102 Helberger, fn 87, s.5.

${ }^{103}$ Crémer et al., fn 3, p.20.

${ }^{104}$ M Vestager, Competition for a Fairer Society, Tenth Annual Global Antitrust Enforcement Symposium Georgetown, 20 September 2016.

${ }^{105}$ Furman et al., fn 4, p.6.
} 
The lack of enforcement of GDPR against US giants directly affects the EU industry's ability to compete. Because DPA chose the lazy way of easy enforcement and Ireland chooses to be a crime haven, the competition interest is meddled with national economic interest. This preserves the competition bias. IMHO, there are three possible resolutions:

a. a race to the bottom (killing GDPR)

b. a simple division of labour (social networking $==$ US \& China vs enterprise computing $==E U$ )

c. a EU action against tax/crime/data protection havens

Web tracking is an example of an open and interoperable environment turning into a cesspool of exploitative practices by both large and small corporate actors.

That doesn't mean that open environments are bad, quite the contrary. But they require governance, beyond code and markets. ${ }^{106}$

On decentralisation, a standards body expert interviewee noted: "ActivityPub and ActivityStreams (AP+AS ) are good basis for system similar to FB and Twitter which are decentralised. (IndieWeb have their own approach, they are hobbyists, piecemeal, solve each problem individually. Only reluctantly standardised AP+AS.) It allows you to have any client you want, and more importantly maybe, and where the data is stored is under the control of the user. That's the key fundamental difference. And it comes at a cost, because of course centralisation helps in terms of performance. It's much harder when things are fully decentralised. So today on FB or Twitter you want to follow me, your clients can access that server, and you get all your friends' posts from the same source, and it's very efficient. But if we said each of your friend will store the data in different places, your client has to open $\mathrm{n}$ connections, download, depend on each and every one of those servers, and present it to you in a form that is suitable. But it does give people control over the data."

S/he added: "The challenge of decentralised systems, they tend inherently to be harder to operate, to set up. All the companies having a Facebook page, it drives me nuts. You see on billboards they gave you a FB page not a web address. People have to register on your website to do anything, it creates friction. This is the challenge we are facing overall. Centralisation reduces friction, makes it very compelling to users."

A free software developer interviewee noted:

${ }^{106}$ W Christl (2020) @WolfieChristl tweet 12:16 20/9/2020. 
The ecosystem should be technically open and you shouldn't need to have permission for your app (and an API key). I do not want to end up with apps being services. This is a big issue with API keys. Once as a developer you apply for an API key, you need to run your software as a service. It is a step forward if you as an individual user can write software to access the services you use. If you want a free software ecosystem you need this. That doesn't empower people. I should be able to fork someone's software, and not reapply, and the more complicated this system is the less likely people will do this. It's a step forward but it remains unfree. (But I can well imagine we end up here. But it would be a compromise.)

API keys as such, but a user should be able to get an API key. I should be able to use any software to log in to any service provider. That is a principle we need to keep emphasising. We need to separate the client and the server side. The server should be neutral to what client I use. That's what the ACCESS Act calls delegation. We should put more focus on the software side of that.

Some academic research has found many messaging users deliberately use noninteroperability as a mechanism to maintain social boundaries by connecting with different groups of partners, friends, family and colleagues via different services. ${ }^{107}$ However, that users today often take advantage of a lack of interoperability doesn't tell us how their usage would change with greater interoperability. There are many types of platform controls that could give users of existing messaging (and social media) better control of their contacts - which would be beneficial for all users for platforms to develop further, and could be incentivised by interoperability. The CMA concluded:

We are conscious that there are potential risks associated with the privacy of users' data, if users lose control over their data, and automatic 'spamming'. However, as long as the decision to post content across platforms is userinitiated and well-informed, including full clarity over permissions, it should be possible to address those concerns. Indeed, we note that users are currently able to cross post content from Instagram to other platforms, such as Facebook, Twitter and Tumblr, which indicates that Facebook can design this functionality in a manner that protects against those concerns. ${ }^{108}$

A significant issue raised by interoperability for data protection is the transfer of users' and their contacts' data to third party systems, the latter without explicit

\footnotetext{
${ }^{107}$ R Arnold, A Schneider and J Lennartz (2020) Interoperability of interpersonal communications services - A consumer perspective, Telecommunications Policy 44, p.4.

${ }^{108}$ CMA, fn 5, Appendix W, p.13.
} 
consent. Even if end-to-end encryption is in place to protect the contents of messages, metadata about messages will still be revealed. ${ }^{109}$

It would be important to develop detailed data protection rules under the General Data Protection Regulation to cover the processing of personal data by third parties using interoperability mechanisms. Civil society group EFF suggests such processing should be limited strictly to that needed to support interoperability, ${ }^{110}$ and MEPs Alexandra Geese and Marcel Koloja have called on the Commission "to introduce an obligation for systemic intermediaries with significant market power to make available and document tools to allow third-parties to interoperate with their main functionalities or to act on an user's behalf, whereby intermediaries may not share, retain, monetize, or use any of the data they receive in the context of interoperability activities from third-parties, and intermediaries and third parties must protect users' privacy and must respect the GDPR and other relevant Union legislation". ${ }^{111}$ The European Data Protection Board has stated (in the context of the interoperability of European contact tracing apps ${ }^{112}$ ):

The goal of interoperability should not be used as an argument to extend the collection of personal data beyond what is necessary. (p.2)

Interoperability will lead to additional processing and disclosure of data to additional entities. As always, data subjects need to be made aware of any additional processing of their personal data and the involved parties. The users should always have a clear understanding of what the use of the application entails and should remain in control of their data. (p.2)

The respective roles, relationships and responsibilities of the joint controllers in regards to the data subject will need to be defined and this information should then be made available to the data subject. (p.3)

Any interoperable solution needs to facilitate a way for data subjects to exercise their rights. Where the exercise of rights is possible, it should not become more cumbersome for the data subjects and it should be clear to whom the data subjects should turn to exercise their rights. (p.4)

\footnotetext{
${ }^{109}$ B Greschbach, G Kreitz and S Buchegger (2012) The devil is in the metadata - New privacy challenges in decentralised online social networks, IEEE International Conference on Pervasive Computing and Communications Workshops, PERCOM Workshops, pp. 333-339.

${ }^{110}$ B Cyphers and C Doctorow, A Legislative Path to an Interoperable Internet, Electronic Frontier Foundation Deeplinks, 28 July 2020.

${ }^{111}$ Amendment 464 to the Draft report by Alex Agius Saliba (PE648.474v02-00), European Parliament Committee on the Internal Market and Consumer Protection, 2020/2018(INL), 18 May 2020.

${ }^{112}$ European Data Protection Board, Statement on the data protection impact of the interoperability of contact tracing apps, adopted 16/6/20.
} 
Differences in the set data retention period should not lead to data being stored for longer than what is necessary. (p.4)

Interoperability should not lead to a decrease in data security and the protection of personal data... This notably concerns security of data in transit for the possible interconnection of back-end servers. In particular, measures addressing security risks related to interoperability that have an impact on the rights and freedoms of natural persons must be addressed in the [Data Protection Impact Assessment]. (p.4)

In a review of the related "data portability" obligations under the GDPR, Facebook noted the views of their stakeholders so far was "a transferring entity may-and should-impose some baseline privacy and data protection restrictions around transfers even when carrying out the transfer to comply with a portability request. But... questions remain about what kinds of conditions are appropriate. ${ }^{\prime 113}$ Facebook suggests there should be clear transparency obligations for the organisation receiving such personal data.

Consideration would also be needed as to the situation of platforms subject to the GDPR or equivalent foreign protection sharing personal data via interoperability mechanisms with other parties that were not. While platforms offering services to Europeans are bound by the GDPR wherever they are established, the situation would be more complex if a GDPR-covered platform A enabled a platform B (that was not) to process personal data relating to a European user accessed on platform A, without that user's explicit consent. The European Data Protection Board notes the importance of ensuring such data is not:

processed in a way that would adversely affect the rights and freedoms of the other data subjects... Such an adverse effect would occur, for instance, if the transmission of data from one data controller to another, would prevent third parties from exercising their rights as data subjects under the GDPR (such as the rights to information, access, etc.).

The data subject initiating the transmission of his or her data to another data controller, either gives consent to the new data controller for processing or enters into a contract with that controller. Where personal data of third parties are included in the data set another legal basis for the processing must be identified. For example, a legitimate interest may be pursued by the data controller under Article 6(1)(f), in particular when the purpose of the data controller is to provide a service to the data subject that allows the latter to process personal data for a purely personal or household activity. The processing operations initiated by the data subject in the context of personal

${ }^{113}$ E Egan, Data Portability and Privacy, Facebook, September 2019, p.10. 
activity that concern and potentially impact third parties remain under his or her responsibility, to the extent that such processing is not, in any manner, decided by the data controller...

Conversely, the rights and freedoms of third parties will not be respected if the new data controller uses the personal data for other purposes, e.g. if the receiving data controller uses personal data of other individuals within the data subject's contact directory for marketing purposes.

Therefore, to prevent adverse effects on the third parties involved, the processing of such personal data by another controller is allowed only to the extent that the data are kept under the sole control of the requesting user and is only managed for purely personal or household needs. A receiving 'new' data controller (to whom the data can be transmitted at the request of the user) may not use the transmitted third party data for his own purposes e.g. to propose marketing products and services to those other third party data subjects...

Furthermore, it is a leading practice for all data controllers (both the "sending" and "receiving" parties) to implement tools to enable data subjects to select the relevant data they wish to receive and transmit and exclude, where relevant, data of other individuals. This will further assist in reducing the risks for third parties whose personal data may be ported.

Additionally, the data controllers should implement consent mechanisms for other data subjects involved, to ease data transmission for those cases where such parties are willing to consent, e.g. if they also want to move their data to some other data controller. Such a situation might arise, for example, with social networks, but it is up to data controllers to decide on the leading practice to follow. ${ }^{114}$

Note that the "legitimate interests" justification for processing cannot be used for "special category" data under $\S 9$ of the GDPR: "personal data revealing racial or ethnic origin, political opinions, religious or philosophical beliefs, or trade union membership, and the processing of genetic data, biometric data for the purpose of uniquely identifying a natural person, data concerning health or data concerning a natural person's sex life or sexual orientation". This would be true of much instant messaging and social media data. It might be that a specific legal provision would be required under $\S 9(f)$ to allow processing of such data from a third party. ${ }^{115}$

\footnotetext{
114 Article 29 Working Party, fn 41, pp.11-12.

115 "processing is necessary for reasons of substantial public interest, on the basis of Union or Member State law which shall be proportionate to the aim pursued, respect the essence of the right to
} 
Note also the limitation identified by the EDPB of the processing of data transferred "for purely personal or household needs." This would again require legislative attention, given the likely use of interoperability provisions by legal persons as well as individuals, and for activities (e.g. proselytising ${ }^{116}$ ) and material (e.g. CCTV footage of public areas recorded by individuals ${ }^{117}$ ) that might not qualify for this GDPR exemption (Recital 18/§2(2)(c)).

The interpretive Recital 18 adds: "Personal or household activities could include correspondence and the holding of addresses, or social networking and online activity undertaken within the context of such activities. However, this Regulation applies to controllers or processors which provide the means for processing personal data for such personal or household activities." So while this provision might protect individual users' personal social networking activities, it would not cover the platforms processing that data.

A platform engineer interview commented: it's important "to protect information about what a startup competitor is doing from the large platform. You need to stop Facebook etc. from using data about competitor in anticompetitive ways (e.g. monitoring the trajectory of new user sign-ups)".

\section{Content moderation}

In both the proposed Digital Services Act package (addressing hate speech, disinformation and extremism) and other legislation (such as the proposed Terrorist Content Regulation ${ }^{118}$ ), the EU is addressing problems relating to "content moderation" by online platforms - the rules and processes by which platforms remove certain "harmful" posts from users, while protecting users' freedom of expression.

Interoperability enables a parallel route by which some of these issues can be addressed - giving users greater choice of different content moderation regimes, even

data protection and provide for suitable and specific measures to safeguard the fundamental rights and the interests of the data subject"

116 Jehovan todistajat, Court of Justice of the European Union, Case C-25/17, 10 July 2018. In the Advocate General's opinion, referring to the similar provision in the GDPR's predecessor Data Protection Directive: "proselytising, by its nature, involves entering into a relationship with persons who are, as a matter of principle, unknown and do not share the preacher's faith. Unlike the holding of a record of addresses, for example, preaching necessarily leads to a 'confrontation' with the world beyond home and family unit. The nature of the data collected, including data enjoying enhanced protection under Directive 95/46, also supports a clear distinction from the example referred to in recital 12 of $\mathrm{Di}$ rective 95/46." Opinion of Advocate General Mengozzi, 1 February 2018, §40.

117 Ryneš v Úřad pro ochranu osobních údajů, Court of Justice of the European Union, Case C-212/13, 11 December 2014. See also L Woods, Bringing Data Protection Home? The CJEU rules on data protection law and home CCTV, EU Law Analysis blog, 11 December 2014.

${ }^{118}$ European Parliament Legislative Observatory, Preventing the dissemination of terrorist content online, 2018/0331(COD). 
on the same platform (separately from the issue of statutory requirements for platforms to remove illegal content).

Mastodon illustrates this possibility. Each of its "instances" (servers) may choose its own moderation rules, with software tools available to ease the work of instance moderators. (In practice, many of the instances choose similar rules.) When new users sign up to Mastodon, they are given the choice of instances that match their own expressed moderation preferences, as shown in Figure 13. Communities of interest can form around specific instances - a comprehensive review found "tech and gaming communities ... quite prominent. Certain topics (e.g. journalism) are covered by many instances, yet have few users. In contrast, other topics (e.g. adult material) have a small number of instances but a large number of users." ${ }^{\prime 19}$ Instances choose which other instances they connect to - some refuse to connect to instances that feature, for example, loose rules around hate speech.

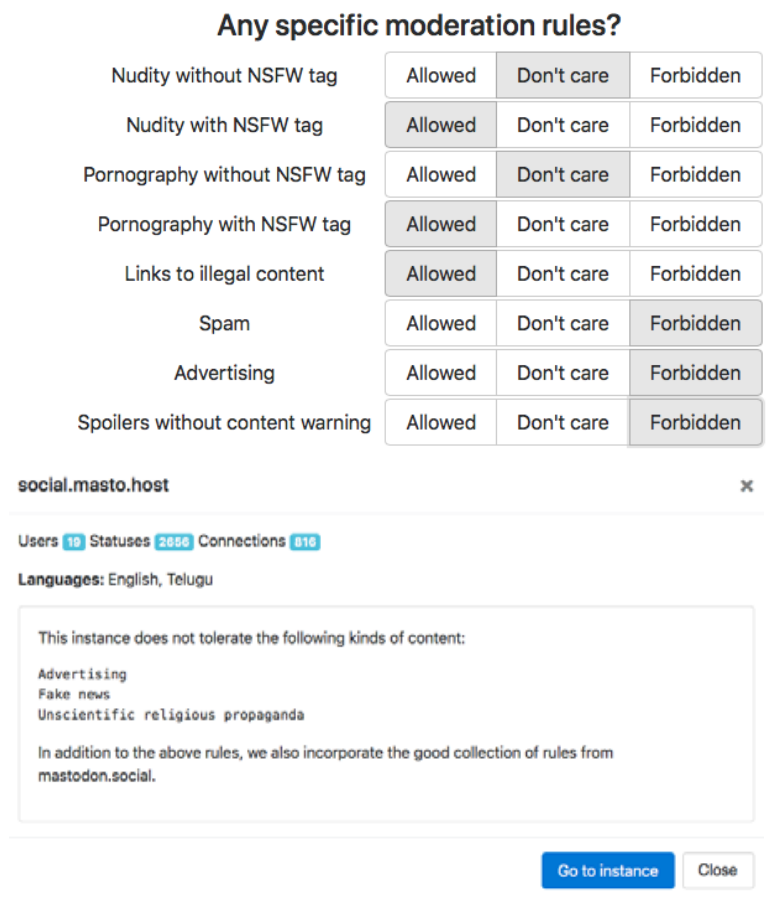

Figure 13 Mastodon helps new users find instances matching their content moderation preferences

${ }^{119}$ A Raman, S Joglekar, E De Cristofaro, N Sastry and G Tyson (2019) Challenges in the Decentralised Web: The Mastodon Case, Proc. Internet Measurement Conference (IMC '19), October 21-23, 2019, Amsterdam. 
The instance run by Mastodon's main developer, Eugen Rochko, has the following content rules: ${ }^{120}$

The following types of content will be removed from the public timeline:

- Excessive advertising

- Uncurated news bots posting from third-party news sources

- Untagged nudity, pornography and sexually explicit content, including artistic depictions

- Untagged gore and extremely graphic violence, including artistic depictions

The following types of content will be removed from the public timeline, and may result in account suspension and revocation of access to the service:

- Racism or advocation of racism

- Sexism or advocation of sexism

- Casteism or advocation of casteism

- Discrimination against gender and sexual minorities, or advocation thereof

- Xenophobic and/or violent nationalism

The following types of content are explicitly disallowed and will result in revocation of access to the service:

- Sexual depictions of children

- Content illegal in Germany and/or France, such as holocaust denial or Nazi symbolism

- Conduct promoting the ideology of National Socialism
Any conduct intended to stalk or harass other users, or to impede other users from utilizing the service, or to degrade the performance of the service, or to harass other users, or to incite other users to perform any of the aforementioned actions, is also disallowed, and subject to punishment up to and including revocation of access to the service. This includes, but is not limited to, the following behaviors:

- Continuing to engage in conversation with a user that has specifically has requested for said engagement with that user to cease and desist may be considered harassment, regardless of platform-specific privacy tools employed.

- Aggregating, posting, and/or disseminating a person's demographic, personal, or private data without express permission (informally called doxing or dropping dox) may be considered harassment.

- Inciting users to engage another user in continued interaction or discussion after a user has requested for said engagement with that user to cease and desist (informally called brigading or dogpiling) may be considered harassment.

An early journalist user reported she found "the predominant culture of mastodon.social isn't San Francisco techies, it's really more of an LGBTQ-oriented space,

${ }^{120}$ E Rochko, mastodon.social Code of Conduct. 
one with a lot of anime avatars and a lot of furries. A veritable multitude of anime avatars, but sans Nazis." ${ }^{21}$ A recent review found "the decentralized structure of Mastodon enables community autonomy", with the federation becoming "a social enterprise in and of itself" due to its open protocol, and that its "horizontal structure shifts the site's scaling focus from sheer number of users to quality engagement and niche communities." 122

Gab, a social media site whose apps were banned from Apple and Google's stores in 2017 due to the presence of "extreme hate speech", now hosts its own (large) Mastodon instance - which is cut off from many other instances. But as the Mastodon code is available under an open source licence, "there's no functional way for Mastodon to shut down Gab. This, of course, was part of the appeal for Gab in the first place. In the past, Gab had lost its webhost GoDaddy and had been banned from accepting donations via PayPal."123

More research is needed on "how federation might encourage hate-speech online and ways to manage those groups", as well as "the extent to which topology, abstraction, and scale facilitate problematic online behavior"124 and the impact of interoperability (and possible controls) on the amplification of harmful content. One possible approach is to develop specific open source licenses to restrict the use of software to propagate extremist content. Another is to block it via software clients rather than instances - which might reduce its spread amongst a broader user base (although not those who specifically choose software to connect to Gab, or similar networks. $)^{125}$

\footnotetext{
${ }^{121}$ S Jeong, Mastodon Is Like Twitter Without Nazis, So Why Are We Not Using It? Motherboard, 4 April 2017.

122 M Liu, RW Gehl and D Zulli (2020) Rethinking the 'Social' in 'Social Media': Insights into Topology, Abstraction, and Scale on the Mastodon Social Network, New Media and Society.

${ }^{123}$ B Makuch, The Nazi-Free Alternative to Twitter Is Now Home to the Biggest Far Right Social Network, Motherboard, 11 July 2019.

${ }_{124}$ Liu et al., fn 122, pp.22-23.

125 J Naskali (2020) Examination of hard-coded censorship in open source Mastodon clients, Proceedings of ETHICOMP 2020: Paradigm Shifts in ICT Ethics.
} 


\section{Environmental impact}

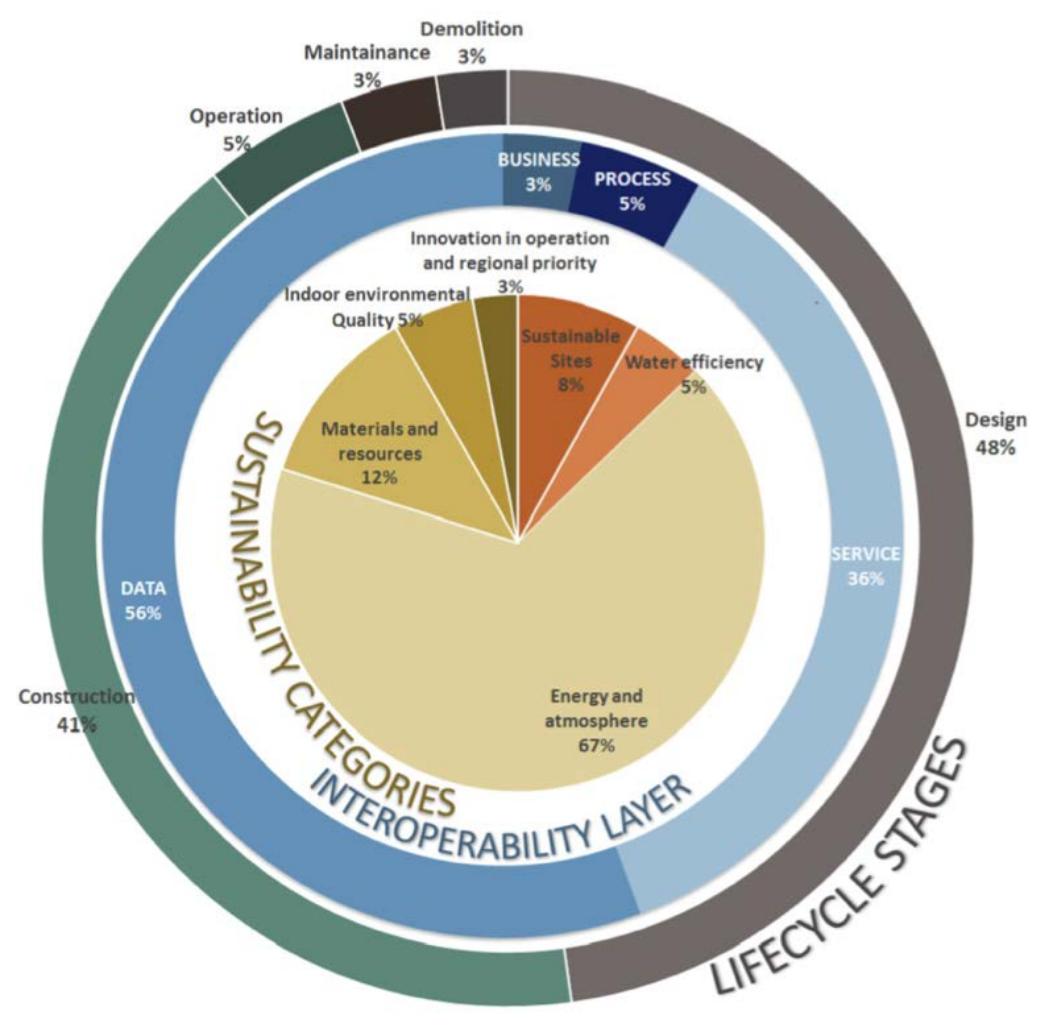

Figure 14 Muller et al.'s framework model for interoperability maturity in the Building Information Modelling lifecycle

In a literature review, Muller and colleagues noted interoperability can support sustainable (real-world) design, construction, operation, maintenance, and demolition, by enabling the exchange of building information between "multidisciplinary teams that are geographically distributed (e.g., owners, architects, consultants, contractors, sub-contractors, suppliers, and engineers)", including energy and sustainability analyses. There are standard data models, ontologies, and encodings for the industry standard Building Information Modeling to enable data and service interoperability (with business and process interoperability also needing attention). The 
authors developed the framework model covering all these issues shown in Figure 14. ${ }^{126}$

A computer scientist interviewee similarly noted:

We should be building future infrastructure such as it's highly interoperable, including new and emergent properties, the disruptive things. It's not just about identifying strategic market status. Legislation should be written to say the future of the Internet is the future of interoperable things. I deeply worry with what's happening with IoT, thinking it in terms of sustainability arguments, we're taking the worst practices of the tech sector, throw everything away after three years, what will that do to the planet. We don't have a single standard across Europe for electricity supply, but we have standards on the quality of the power supply, 240V. But nations insisted on e.g. square plugs. That affects everyone. It's about the infrastructure. You wouldn't let startups say we want our self-driving car to drive on the right-hand side. IoT needs to be in the building regs to get it under control. Then compete on quality of product, not our plug is easier to use than your plug. So, I do think there's a general background to this, we shouldn't be permitting to get to this point. People will have to throw away all their tech when they move to a new house. And it's even worse when it gets embedded in the building. Number of things so completely wrong with the loT at the moment. It's the emergent mayhem in that sector. It's just a complete mess. Much more here about interop being the basis for a sustainable economy rather than a very wasteful one. The number of IOT device companies Google has just shut down after acquiring them, all that tech is on the scrapheap. We're building all sorts of problems here that aren't economic, but sustainability.

\section{Digital sovereignty}

There are obvious political issues with democratically unaccountable private powers of historically unprecedented size, ${ }^{127}$ with Amazon, Microsoft, Facebook, Alphabet and Apple in mid-2020 together approaching a quarter of the value of the US's largest 500 listed companies. ${ }^{128}$ The five companies' collective 2019 revenues places them between the Netherlands and Saudi Arabia, when countries are ranked by GDP. ${ }^{129}$ These companies are all headquartered in a jurisdiction with an extremely

\footnotetext{
${ }^{126}$ M Figueiredo Muller*, F Esmanioto, N Huber, E Rocha Loures, O Canciglieri Jr. (2019) A systematic literature review of interoperability in the green Building Information Modeling lifecycle, Journal of Cleaner Production, Vol. 223, pp.408-409.

127 N Smyrnaios (2016) The GAFAM effect: Strategies and logics of the internet oligopoly, Communication \& Languages, Vol. 188(2), pp.61-83.

${ }^{128}$ Lex, Techlash: all talk, Financial Times, 14 June 2020.

${ }^{129}$ Wallach, fn $67 .$.
} 
laissez faire approach to regulation - or alternatively, as with Chinese giants such as Alibaba, Tencent and Baidu, the world's most populous authoritarian state.

Big Tech Revenues (2019 vs. 2018)

\begin{tabular}{llll}
\hline Company & Revenue (2018) & Revenue (2019) & Growth (YoY) \\
\hline Apple & $\$ 265.6$ billion & $\$ 260.2$ billion & $-2.03 \%$ \\
\hline Amazon & $\$ 232.9$ billion & $\$ 280.5$ billion & $20.44 \%$ \\
\hline Alphabet & $\$ 136.8$ billion & $\$ 161.9$ billion & $18.35 \%$ \\
\hline Microsoft & $\$ 110.4$ billion & $\$ 125.8$ billion & $13.95 \%$ \\
\hline Facebook & $\$ 55.8$ billion & $\$ 70.8$ billion & $26.88 \%$ \\
\hline Combined & $\$ \mathbf{8 0 1 . 5}$ billion & $\$ \mathbf{8 9 9 . 2}$ billion & $\mathbf{1 2 . 1 9 \%}$ \\
\hline
\end{tabular}

Table 2: 2018 and 2019 revenues of Apple, Amazon, Alphabet, Microsoft and Facebook. Source: Wallach (2020)

This is a particular issue when these firms control the 21st century "public squares" of the Internet, where so much social and political debate now occurs. While the EU has responded with legislation such as the General Data Protection Regulation, which also applies to companies in other jurisdictions offering services to or monitoring Europeans, this cannot on its own address the increasingly outsized influence of trillion-dollar companies on politics and everyday life. Interoperability would allow European companies - large and small - to produce alternative tools for Europeans to connect to these public squares, as well as their colleagues, friends and family, if they so wished.

Paul Nemitz, a senior European Commission official who played a key role in the development of the GDPR, commented in an on-the-record interview:

Like states, the big tech companies are now so powerful we now need to think about the division of power. From the point of view of democracy, if one believes humanity and technology's innovativeness is unlimited, and it leads ever more to concentration, we have a huge democracy problem, because democracy cannot live with the fact the platform starts as social media, then takes over schools and education, then journalism, then research, then onto elections... no.

Then comes the question, how can we support innovation? There are many who say the fact these companies systematically either buy up, imitate, or push to the side any little flower that comes up that could be an alternative or a competitor, is a huge impediment to innovation which is impossible to manage with a purely ex post competition tool where you have to spend three years on every case. These cannot not be dealt with on a case by case basis. 
How many hundreds of companies have been bought up by them? The companies are good where they are, so European industrial policy has to go to other places. Internet of Things - let's look at that. Something where we can start anew. But we cannot imitate what they are doing well. We must do new things newer and better, and we must create the conditions for success.

As European Commission president Ursula von der Leyen wrote, "'tech sovereignty' ... describes the capability that Europe must have to make its own choices, based on its own values, respecting its own rules. This is what will help make tech optimists of us all." ${ }^{130}$

${ }^{130}$ U von der Leyen, Shaping Europe's digital future, 19 February 2020. 


\section{Existing and planned European interopera- bility policies}

The EU has a long history of using interoperability as a policy tool to overcome network effects and high switching costs in concentrated markets such as telecommunications and banking, and foresees its use in a wide range of future digital services:

- The Access Directive (2002/19/EC) aims to "establish a regulatory framework... for the relationships between suppliers of networks and services that will result in sustainable competition, interoperability of electronic communications services and consumer benefits." (§1)

- The Framework Directive (2002/21/EC) requires Member States to encourage the use of communications standards where required "to ensure interoperability of services and to improve freedom of choice for users. (§17)

- The European Electronic Communications Code (EECC, 2018/1972) aims to "implement an internal market in electronic communications networks and services that results in the deployment and take-up of very high capacity networks, sustainable competition, interoperability of electronic communications services, accessibility, security of networks and services and enduser benefits" (§1(2)(a)). It includes provisions on instant messaging ("number-independent interpersonal communications service") (§61), which are yet to be used by the competent national authorities. In particular, authorities may impose, "in justified cases, where end-to-end connectivity between end-users is endangered due to a lack of interoperability between interpersonal communications services, and to the extent necessary to ensure end-to-end connectivity between end-users, obligations on relevant providers of number-independent interpersonal communications services which reach a significant level of coverage and user uptake, to make their services interoperable".

- The second Payment Services Directive (2015/2366) provides an enabling framework for secure, innovative financial services, requiring the European Banking Authority to develop "open standards [which] should ensure the interoperability of different technological communication solutions" (Recital 93).

- Competition law enforcement by the European Commission required Microsoft to provide a choice of web browsers in its Windows operating system, and to allow workgroup software to network Windows PCs; and Google to provide a choice of default search engine in its Android browser, and to allow alternate specialised search engines to bid for inclusion in its main results page.

- The Digital Future Communication explicitly mentions interoperability as part of the policies on $5 \mathrm{G}$ and $6 \mathrm{G}$; digital health; elD; supercomputing; quantum technologies; blockchain; secure, pan-European cloud capacities; and exchange of electronic health records. 
- The Communication on A European Strategy for Data states that data interoperability is key for the exploitation of data value, as well as a tool for increased competition by making it easier to switch between cloud providers.

- The European Commission is supporting the Member States to ensure their coronavirus contact tracing apps are interoperable, enabling travellers to be notified following a foreign trip if they were significantly exposed to someone who later tested positive.

- The commonly-called Platform to Business Regulation (2019/1150) also provides important underpinnings, relating to transparency and fairness of all "intermediation services" and search engines linking businesses and corporate websites with consumers, including on access to data. ${ }^{131}$

The interoperability explicitly foreseen in the Electronic Communication Code between number-independent interpersonal communications services (aka instant messaging) may only be imposed:

(i) to the extent necessary to ensure interoperability of interpersonal communications services and may include proportionate obligations on providers of those services to publish and allow the use, modification and redistribution of relevant information by the authorities and other providers, or to use and implement standards or specifications listed in Article 39(1) or of any other relevant European or international standards;

(ii) where the Commission, after consulting BEREC and taking utmost account of its opinion, has found an appreciable threat to end-to-end connectivity between end-users throughout the Union or in at least three Member States and has adopted implementing measures specifying the nature and scope of any obligations that may be imposed. (\$61(2))

While some types of interoperability have been imposed ex post (following a European Commission investigation and decision-making process) in specific cases under existing rules, many competition economists judge these detailed and highly fact-specific cases too slow (seven years, in some cases), unpredictable, and narrow to provide the broader rules needed for effective digital competition. ${ }^{132}$ Tirole notes: "it is slow. A fine on an incumbent for anticompetitive behavior may serve as a deterrent for future such behavior, but it does not really help the entrant that went belly up in between... Competition policy in the digital age must achieve speedy and

\footnotetext{
${ }^{131}$ Regulation (EU) 2019/1150 of the European Parliament and of the Council of 20 June 2019 on promoting fairness and transparency for business users of online intermediation services, OJ L 186, 11.7.2019, p. 57-79.

${ }^{132}$ Furman et al., fn 4, p.55
} 
decisive resolution and must be agile to react to new environments and benefit from learning-by-doing." ${ }^{133}$ A standards body expert interviewee commented:

I find it appalling we still don't have standard messaging protocol that is universally used, and maybe some clients have added features but at least you'd be able to communicate with anyone. But currently we have to agree which product we want to use. E.g. Slack and Skype don't co-exist at all. It's like saying I have a Motorola phone and can communicate only with other Motorola users.

I am saddened to see the trend is very negative, because we are moving towards more and more centralised systems. Slack is a very good example. Facebook is sort of new, Twitter is sort of new as well. Slack actually builds on a protocol which is existing, IRC, and then managed to hijack this system by adding features that only their clients initially supported. You could still access the information with the standard protocol and therefore standard client, but they kept adding more and more on top, so it becomes impossible. $I R C$ is pretty decentralised; anyone could set up an IRC server and communicate with any client you liked. But now we are all bound to Slack servers. You can have different ones e.g. business, but they have drawn you into their environment, which is centralised around Slack.

It's very frustrating and scary to see that everything becomes more and more centralised, and some of the old systems which were designed in a very decentralised way and we take for granted. One of the next things on the list might be e-mail. For now, it's still decentralised, you can use whatever client you want. Google has been making Gmail available for everybody. But you start to see features that only work with other Gmail users, and this is the start of a slippery slope. And the mass of users they have give them a momentum that is very hard to fight.

A computer scientist interviewee added: "Nearly all of the original IM systems were based on IP, then for reasons people played winner takes all game and stopped interoperating. People noticed you could leverage network effects. There is nothing on any of these platforms you couldn't do with a standard thing. Then you get differentiation. That comes down to the client. The protocols are standard. Mobile phone network, W3C, IETF — this is a system that's been running for decades. Going back to ITU 19th century. Regulators got blinded by this idea of data railway tracks."

The recent major reviews of platform competition for the DG Competition, UK government and US Stigler Center have all found the use of investigations followed by ex post remedies too slow to cope with these fast-moving technologies and

${ }^{133}$ Tirole, fn 21, pp.6-7. 
markets. The UK Furman review concluded: "The key limitation of using market investigations as the legal basis for a pro-competition approach is that its remedies are largely static. Binding orders cannot be revised and updated as the nature of solutions needed changes... Relying on this model alone, under the powers currently available, is not sufficient in digital markets when technologies change but market power is durable. Specific rules imposed as a remedy following a market investigation may quickly go out of date. What is instead needed is an ongoing, dynamic counterparty to market participants, adjusting solutions in response to innovations and market dynamics." ${ }^{134}$ Regulations can set ex ante rules, while still leaving open the option for later enforcement of standard competition law. ${ }^{135}$

Several governments and legislatures have produced draft competition legislation mandating interoperability for large online platforms. Table 3 summarises key elements:

\begin{tabular}{|c|c|c|}
\hline & US ACCESS bill (S. 2658) & $\begin{array}{l}\text { French consumers' free } \\
\text { choice in cyberspace bill }\end{array}$ \\
\hline Status & $\begin{array}{l}\text { Introduced } 22 / 10 / 19 \text { and referred to Sen- } \\
\text { ate Committee on Commerce, Science, } \\
\text { and Transportation }\end{array}$ & $\begin{array}{l}\text { Passed by Senate Feb. } \\
2020 \text {; awaiting considera- } \\
\text { tion by National Assembly } \\
\text { Committee on Economic } \\
\text { Affairs }\end{array}$ \\
\hline $\begin{array}{l}\text { Applica- } \\
\text { ble to }\end{array}$ & $\begin{array}{l}\text { "a consumer-facing communications and } \\
\text { information services provider" which "gen- } \\
\text { erates income, directly or indirectly, from } \\
\text { the collection, processing, sale, or sharing } \\
\text { of user data" with > 100m monthly active } \\
\text { users in the US }\end{array}$ & $\begin{array}{l}\text { "online platform operators } \\
\text { whose activity exceeds a } \\
\text { threshold of number of } \\
\text { connections defined by de- } \\
\text { cree." }\end{array}$ \\
\hline $\begin{array}{l}\text { Specific } \\
\text { mandate }\end{array}$ & $\begin{array}{l}\text { "maintain a set of transparent, third-party- } \\
\text { accessible interfaces (including APIs) to } \\
\text { facilitate and maintain technically compat- } \\
\text { ible, interoperable communications with a } \\
\text { user of a competing communications pro- } \\
\text { vider." }\end{array}$ & $\begin{array}{l}\text { "1. The publication of rele- } \\
\text { vant information; } \\
\text { " } 2 \text {. The authorization of the } \\
\text { use, modification and re- } \\
\text { transmission of this infor- } \\
\text { mation by ARCEP or other } \\
\text { operators of online plat- } \\
\text { forms" }\end{array}$ \\
\hline
\end{tabular}

\footnotetext{
${ }^{134}$ Furman et al., fn 4, p.79

${ }^{135}$ Graef, fn 8, s.3.2.
} 


\begin{tabular}{|c|c|c|}
\hline $\begin{array}{l}\text { Stand- } \\
\text { ardisa- } \\
\text { tion }\end{array}$ & $\begin{array}{l}\text { FTC, "in consultation with relevant industry } \\
\text { stakeholders, shall establish rules and pro- } \\
\text { cedures to facilitate the verification of the } \\
\text { validity of requests from users and com- } \\
\text { peting communications providers to obtain } \\
\text { user data" } \\
\text { NIST "shall develop and publish model } \\
\text { technical standards by which to make in- } \\
\text { teroperable popular classes of communi- } \\
\text { cations or information services, including- } \\
\text { (1) online messaging; } \\
\text { (2) multimedia sharing; and } \\
\text { (3) social networking." } \\
\text { "Any large communications platform pro- } \\
\text { vider that establishes and maintains in- } \\
\text { teroperability through an open standard } \\
\text { established under subsection (c) shall be } \\
\text { entitled to a rebuttable presumption of } \\
\text { providing access on fair, reasonable, and } \\
\text { nondiscriminatory terms." }\end{array}$ & $\begin{array}{l}\text { ARCEP may impose "imple- } \\
\text { mentation of technical in- } \\
\text { teroperability standards } \\
\text { identified by the authority." }\end{array}$ \\
\hline $\begin{array}{l}\text { Security } \\
\text { and pri- } \\
\text { vacy }\end{array}$ & $\begin{array}{l}\text { "A large communications platform provider } \\
\text { shall, consistent with industry best prac- } \\
\text { tices, set privacy and security standards } \\
\text { for access by competing communications } \\
\text { services to the extent reasonably neces- } \\
\text { sary to address a threat to the large com- } \\
\text { munications platform or user data, and } \\
\text { shall report any suspected violations of } \\
\text { those standards to the [FTC]." } \\
\text { "A competing communications provider } \\
\text { that accesses an interoperability interface } \\
\text { of a large communications platform pro- } \\
\text { vider shall reasonably secureany user data } \\
\text { it acquires, processes, or transmits." }\end{array}$ & $\begin{array}{l}\text { ARCEP must consult with } \\
\text { National Commission for } \\
\text { Informatics and Liberties } \\
\text { Before imposing interoper- } \\
\text { ability obligations }\end{array}$ \\
\hline $\begin{array}{l}\text { Enforce- } \\
\text { ment }\end{array}$ & General FTC Act powers & $\begin{array}{l}\text { The Minister and ARCEP } \\
\text { may "collect from the oper- } \\
\text { ators of online platforms } \\
\text { the information or docu- } \\
\text { ments necessary to ensure } \\
\text { that these persons comply }\end{array}$ \\
\hline
\end{tabular}




\begin{tabular}{|l|l|}
\hline \begin{tabular}{|l|l|}
\hline with the obligations laid \\
down"
\end{tabular} & $\begin{array}{l}\text { ARCEP may "penalize any } \\
\text { breaches it finds" }\end{array}$ \\
\hline
\end{tabular}

Table 3: key provisions of draft US and French interoperability legislation

In assessing the 25-year history of the European telecommunications regulatory framework, Cave, Genakos and Valletti concluded:

Within the period of a quarter of a century or so, the European telecommunications sector has been radically transformed from a group of state monopolies to a set of increasingly competitive national markets. This has been accomplished within the framework of a flexible regime of regulation, which combines significant deregulatory momentum with detailed implementation by national regulatory authorities. Liberalisation under independent regulation was an appropriate response to the technological and economic changes at the industry level, as well as the political conditions at the time. It facilitated the entry of new firms and increased competition. The rapid diffusion of new technologies and new services led to falling prices and much greater take up, which had wider beneficial effects on the European economy. It is fair to say that, overall, telecommunications markets represent one of the success stories of EU policy-making in network industries. ${ }^{136}$

A standards body expert interviewee noted:

From an EU legal tech point of view, with a new approach, like we have done for e-signatures, where you have an Art. 9 committee that will make a European norm, by ETSI etc. then it can beacknowledged, then taken up in a norm saying you need to provide data in a standardised format. That gives the industry an incentive to be part of that standardisation because they want to have certain data points in there.

A free software developer interviewee added:

Having regulators oblige specific standards sounds undesirable (with exceptions), as I suspect it would slow things down terribly. Setting high-level requirements on capabilities of software and services sounds better; e.g. demanding the ability to connect using 3rd party software, and interact with non-members as easily as with members. Companies can pick or create the

\footnotetext{
${ }^{136}$ M Cave, C Genakos and T Valletti (2019) The European Framework for Regulating Telecommunications: A 25-year Appraisal, Review of Industrial Organization, vol. 55, p.60.
} 
standards, as long as those fulfil the requirements, which are assessed by a regulator; much like net neutrality.

Perhaps some dominant companies would make compliant but shitty standards on purpose (thinking of Microsoft's Office Open XML), so some more scrutiny may be required for those. And current incumbents might need extra interventions (e.g. splitting them up) to get things rolling. 


\section{Appendix 1 - Types of interoperability and example scenarios}

The International Standards Organisation (ISO), in its standard on cloud interoperability, defines the term as "the ability of two or more systems or applications to exchange information and to mutually use the information that has been exchanged." 137

Interoperability can be both partial and unidirectional. For example, an instant messaging platform might allow a competitor service to send its users text and images, but not video; and not allow its own users to reply. A mobile operating system could allow an app to use all the standard features of a smartphone, but not to access special security hardware (as in the case of Apple Pay under investigation by the European Commission.) These obstacles can be due to the costs of developing interoperable service features; valid quality and security concerns (for which there are other protective mechanisms, which still enable interoperability); and straightforward business reasons, such as discouraging customers from using competitor products. ${ }^{138}$

The UK's Competition and Markets Authority determined: "Given the market position of Facebook and the extent to which it benefits from network effects, we think that [interoperability] interventions should apply asymmetrically to Facebook in the first instance (e.g. Facebook should offer a defined find friends service to users of a third-party platform, but rival platforms should not be required [to] reciprocate). The balance of considerations is likely to change over time: the fast-evolving nature of social platforms means that the [regulator] will be well-placed to judge the right forms of interoperability to deliver consumer benefits on an ongoing basis." 139

An additional distinction is between "syntactic/technical interoperability", the ability for systems to connect and exchange data, and "semantic interoperability", that connected systems share a common understanding of the meaning of data they exchange. ${ }^{140}$

\footnotetext{
137 ISO/IEC 19941: 2017, p.vi.

${ }^{138}$ Kerber \& Schweitzer, fn 91, p.4.

${ }^{139}$ CMA, fn 5, p.374.

140 Kerber \& Schweitzer, fn 91, p.4.
} 


\section{Vertical and horizontal interoperability}

Vertical interoperability enables a person to freely choose a combination of devices/operating systems, software/apps, and service providers (including search). ${ }^{141}$ These are complementary products/services, and so providers have a greater incentive to enable interoperability if it can add value to their own offering (unless, of course, they also offer their own neighbouring services, and/or profit from charging providers for access, such as in smartphone app stores.) For example, with the necessary software support, a user could:

- Edit a report on an iPad using the Word app while storing it in Dropbox (this is possible today, due to action by Apple, Microsoft and Dropbox).

- Follow their news feed on their Android-running Fairphone using the Feedly app, logging into Twitter and Facebook (Twitter allows software from other organisations to access *some* of its features, allowing users to read their timeline and tweet with other tools, but blocks developers from replicating its "core user experience or features". Facebook allows other forms of software integration, including posting, but until December 2018 banned competitors from connecting to its APIs to replicate its core functionality ${ }^{142}$ ).

- Choose a different search engine as a default for their Android web browser, or different default browser for their Windows PC (both possible in Europe thanks to EU competition enforcement using existing rules).

- Use alternative App Stores (possible on Android but not iOS), and payment apps (other than Apple Pay) which have access to iPhone's secure chip (as the European Commission's DG Competition is currently investigating).

Interoperable products and platforms can be more valuable for consumers, and hence firms selling them. Using standardised, interoperable components can reduce production costs. However, firms focused on innovative and/or high-quality luxury products - such as Apple - may prefer to retain control over components (e.g. chargers and cables) and complementary products (such as checking app security), especially since this can lead to royalties/commissions, higher profits, and greater investment. ${ }^{143}$

Horizontal interoperability enables people to use different products and service providers than the people they interact with. ${ }^{144}$ Since those are substitute offerings, firms may be less willing to voluntarily enable competitors' access to their user base. For example, with the necessary software support:

\footnotetext{
${ }^{141}$ Kerber \& Schweitzer, fn 91, p.4.

142 CMA, fn 5, Appendix W, p.2.

${ }^{143}$ Kerber \& Schweitzer, fn 91, p.6

${ }^{144}$ Kerber \& Schweitzer, fn 91, p.4
} 
- A Telegram user could directly chat with a family WhatsApp group. (Facebook is already developing the ability for users of its Messenger, WhatsApp and Instagram services to message each other. It allowed third-party chat software to contact its users from 2010-2015. ${ }^{145}$ )

- A Flickr user could follow the pictures posted by their sports team via a private account on Instagram.

- A university student using TikTok could see videos recommended by their flatmates on YouTube.

- A Facebook Messenger user could try out Snapchat (multi-homing) while still using their profile information and being able to message friends on Messenger directly. ${ }^{146}$

- A teacher using Facebook could invite their students' parents to a class event and receive RSVPs, whether parents use Facebook, Google Calendar, iCal, or an open source calendar.

\section{Protocol and data interoperability}

Margrethe Vestager's 2019 special advisers' report on digital competition identified three types of interoperability:

1. Protocol interoperability - "the ability of two services or products to interconnect, technically, with one another." Examples: DG Competition decisions on Microsoft in 2004 (compatibility of Sun workgroup servers) and 2009 (tying of Internet Explorer to Windows). This mainly enables complementary services rather than direct substitutes.

2. Full protocol interoperability - "standards that allow substitute services to interoperate, e.g. messaging systems." Benefit: "through the imposition of interoperability requirements, the benefits of positive network effects can be shared among direct competitors. In this perspective, interconnection could be an efficient instrument to address concentration tendencies." But "the need for strong standardisation across several competing platforms could significantly dampen their ability to innovate and to differentiate the type(s) of service(s) they provide" and "the need for coordination between the firms affected by the requirement would provide opportunities for collusive behaviour." This can be dealt with by open standards for core functionality in mature systems (see later).

3. Data interoperability - "roughly equivalent to data portability but with a continuous, potentially real-time, access to personal or machine user data. Existing data interoperability mechanisms typically rely on privileged APIs,

\footnotetext{
145 Zoom support, Facebook and Google To Discontinue XMPP Chat Protocol, undated.

146 One former official interviewee commented: "On [messaging] tools, there's more partial substitutability between different tools that allows tool hopping. So generally there's a lot more competition around. That said, there's clearly still a big pull towards WhatsApp."
} 
which provide to a service $B$ the means to access its users' data through a service A's API, if the users have given authorisation for this transfer of data." (Data interoperability requires at least basic protocol interoperability, so data can be requested and provided.)

\section{Detailed technical and regulatory examples}

The following scenarios provide very specific examples of user benefits deriving from various types of interoperability that could be imposed on dominant platforms using the current EU regulatory framework, and potential powers under the Digital Markets Act. They are focused on messaging and social media platforms within the existing EU regulatory framework (GDPR + ePrivacy, consumer protection, electronic communications framework directive, or existing market practices), and based on open protocols (standardised and governed using the existing EU regulatory framework described later).

\section{Straightforward within existing regulatory framework}

\begin{tabular}{|c|c|c|}
\hline Example & User benefit & Regulatory mechanism \\
\hline $\begin{array}{l}\text { Users are given access to } \\
\text { their personal data held by a } \\
\text { platform in whichever tool } \\
\text { they choose (independent } \\
\text { from platforms' own 'data } \\
\text { management' and 'export' } \\
\text { settings), via a standardised } \\
\text { API and security mechanisms. }\end{array}$ & $\begin{array}{l}\text { Give users practical control } \\
\text { over their personal data and } \\
\text { tools. } \\
\text { Enable development of user- } \\
\text { friendly tools to show and ex- } \\
\text { plain to users what data is } \\
\text { held by platforms. }\end{array}$ & $\begin{array}{l}\text { A stronger risk-based ap- } \\
\text { proach to GDPR data portabil- } \\
\text { ity right (Art.20) by EDPB/na- } \\
\text { tional supervisory authorities. } \\
\text { Issue further EDPB guidance, } \\
\text { enforced by national data } \\
\text { protection authorities, coordi- } \\
\text { nated via EDPB. }\end{array}$ \\
\hline $\begin{array}{l}\text { "One click" data portability } \\
\text { (independent from platforms' } \\
\text { own 'data management' set- } \\
\text { tings) - user can download } \\
\text { and delete data using stand- } \\
\text { ard tools, and upload to new } \\
\text { platform; or authorise new } \\
\text { platform to directly access } \\
\text { (and optionally delete) data. } \\
\text { "Real-time" data portability. }\end{array}$ & $\begin{array}{l}\text { Help users move/copy data } \\
\text { between platforms (easy } \\
\text { switching/multi-homing be- } \\
\text { tween providers) } \\
\text { Enable enhanced price com- } \\
\text { parison and other tools that } \\
\text { need access to user profiles } \\
\text { (Open } X \text {, eg banking, finance, } \\
\text { communications...) }\end{array}$ & $\begin{array}{l}\text { EC-initiated standardisation } \\
\text { activity. } \\
\text { Vestager's special advisers } \\
\text { (p58): "A competition policy } \\
\text { perspective would suggest } \\
\text { that dominant platforms could } \\
\text { be subject to stricter [GDPR } \\
\text { portability]" }\end{array}$ \\
\hline $\begin{array}{l}\text { Give users a broader scope of } \\
\text { personal data that can be ac- } \\
\text { cessed/transferred - inferred, } \\
\text { and processed for a wider }\end{array}$ & $\begin{array}{l}\text { Supports genuine "data port- } \\
\text { ability" and multi-homing. }\end{array}$ & $\begin{array}{l}\text { Minor amendment to GDPR } \\
\text { Art. 20, via DMA, or ePrivacy } \\
\text { Regulation. Enforced by na- } \\
\text { tional data protection author- } \\
\text { ities, coordinated via EDPB. }\end{array}$ \\
\hline
\end{tabular}




\begin{tabular}{|c|c|c|}
\hline $\begin{array}{l}\text { range of purposes, on domi- } \\
\text { nant platforms. }\end{array}$ & & \\
\hline $\begin{array}{l}\text { Ability to send private mes- } \\
\text { sages to users (and user } \\
\text { groups) on other platforms, } \\
\text { when authorised by recipi- } \\
\text { ents. }\end{array}$ & $\begin{array}{l}\text { Lets users message their } \\
\text { friends, family and colleagues } \\
\text { on other messaging plat- } \\
\text { forms, without having to } \\
\text { switch or multi-home. } \\
\text { Let users participate in } \\
\text { groups from a single, pre- } \\
\text { ferred messaging app (e.g. } \\
\text { avoiding profiling by having } \\
\text { an account with an advertis- } \\
\text { ing-funded platform). }\end{array}$ & $\begin{array}{l}\text { Decision under European } \\
\text { Electronic Communications } \\
\text { Code (EECC). Enforced by } \\
\text { national communications au- } \\
\text { thorities, coordinated via BE- } \\
\text { REC. } \\
\text { EC-initiated standardisation } \\
\text { activity (with consideration of } \\
\text { IETF standards such as } \\
\text { SIP/SIMPLE and XMPP.) }\end{array}$ \\
\hline $\begin{array}{l}\text { Free choice of client to man- } \\
\text { age data/privacy and profiling } \\
\text { settings [eg MyData.org } \\
\text { model], with tools developed } \\
\text { by software companies and } \\
\text { civil society/consumer groups } \\
\text { to help manage complex set- } \\
\text { tings. }\end{array}$ & $\begin{array}{l}\text { Ensures genuine choice and } \\
\text { control for users, rather than } \\
\text { giving up their data and rights } \\
\text { due to excessively complex } \\
\text { and opaque controls (so- } \\
\text { called "dark patterns"). }\end{array}$ & $\begin{array}{l}\text { Arguable under Unfair Terms } \\
\text { Directive (Graef et al. p.204: } \\
\text { "unfairness consists of sub- } \\
\text { stantive elements (including } \\
\text { 'good faith' and 'significant } \\
\text { imbalance' components to be } \\
\text { assessed at the national level) } \\
\text { and formal elements (trans- } \\
\text { parency and information pro- } \\
\text { vision) as contained in Arti- } \\
\text { cles 3-5 of the Directive... fo- } \\
\text { cuses on the average con- } \\
\text { sumer's capacity to make in- } \\
\text { formed autonomous deci- } \\
\text { sions"), or minor update via } \\
\text { DMA } \\
\text { Enforced by DG coMP/EU } \\
\text { digital market agency/ na- } \\
\text { tional competition and con- } \\
\text { sumer authorities. }\end{array}$ \\
\hline
\end{tabular}


New but less controversial scenarios (based on past experience from other sectors)

\begin{tabular}{|c|c|c|}
\hline Example & User benefit & Regulatory mechanism \\
\hline $\begin{array}{l}\text { Ability to use different client } \\
\text { software than the app(s) the } \\
\text { platform provides itself. }\end{array}$ & $\begin{array}{l}\text { Greater user choice, to find } \\
\text { tools that best meet their } \\
\text { needs and values } \\
\text { Don't allow the bundling of } \\
\text { dominant platform user inter- } \\
\text { face and infrastructure - for } \\
\text { example, let user choose their } \\
\text { own curation/ recommenda- } \\
\text { tion algorithms from third } \\
\text { party providers. }\end{array}$ & $\begin{array}{l}\text { Ex ante interoperability rule in } \\
\text { DMA for large online plat- } \\
\text { forms, with enforcement by } \\
\text { DG COMP/EU digital market } \\
\text { agency/national competition } \\
\text { authorities. } \\
\text { The platform should not fa- } \\
\text { vour (its own) specific apps } \\
\text { (no self-preferencing, tying, } \\
\text { or privileged APIs) - CMA - } \\
\text { and must implement proto- } \\
\text { cols/APIs that enable third } \\
\text { party developers to create } \\
\text { equivalent functionality in } \\
\text { their apps. } \\
\text { EC-initiated standardisation } \\
\text { recognition relating to W3C } \\
\text { ActivityPub and relevant } \\
\text { messaging standards. }\end{array}$ \\
\hline $\begin{array}{l}\text { Ability for user tools to send a } \\
\text { standard signal for express- } \\
\text { ing tracking and targeting } \\
\text { preferences ('New DNT'), } \\
\text { which can be managed via } \\
\text { user's browser or another in- } \\
\text { dependent intermediary. Ex- } \\
\text { ample of "semantic interoper- } \\
\text { ability". }\end{array}$ & $\begin{array}{l}\text { Users would be able to com- } \\
\text { municate consent/non-con- } \\
\text { sent for data processing, } \\
\text { avoiding endless cookie no- } \\
\text { tices and preferences. }\end{array}$ & $\begin{array}{l}\text { Exante rule in DMA for all ser- } \\
\text { vices processing personal } \\
\text { data, and/or consent rule in } \\
\text { ePrivacy Regulation, with en- } \\
\text { forcement by DG COMP/other } \\
\text { Brussels digital market } \\
\text { agency/national competition } \\
\text { and data protection authori- } \\
\text { ties. } \\
\text { EC-initiated standardisation } \\
\text { and recognition activity relat- } \\
\text { ing to W3C Do-Not-Track and } \\
\text { its successors. }\end{array}$ \\
\hline $\begin{array}{l}\text { Protection of open identities: } \\
\text { wherever the closed single } \\
\text { sign-on systems (i.e. sign in } \\
\text { with Facebook / Google / Ap- } \\
\text { ple) are supported, at least } \\
\text { one open and federated }\end{array}$ & $\begin{array}{l}\text { Greater user choice, to find } \\
\text { identity tools that best meet } \\
\text { their needs and values. } \\
\text { Supports EU data protection }\end{array}$ & $\begin{array}{l}\text { DMA, GDPR update/ guidance } \\
\text { from EDPB, and/or ePrivacy } \\
\text { Regulation. Soft regulatory } \\
\text { tools (eg standardisation and } \\
\text { governance) of elDAS. }\end{array}$ \\
\hline
\end{tabular}


identity system should be supported as well, including eIDAS. framework, by reducing leakage of personal data to identity providers not focused on privacy.
Enforced by DG COMP/EU digital market agency/ national competition and data protection authorities.

\section{New and morechallenging scenarios}

\begin{tabular}{|c|c|c|}
\hline Example & User benefit & Regulatory mechanism \\
\hline $\begin{array}{l}\text { User gets read/write access } \\
\text { to feeds produced by users of } \\
\text { other platforms (with their au- } \\
\text { thorisation) without needing } \\
\text { to create their own account. }\end{array}$ & $\begin{array}{l}\text { Users can choose any tool or } \\
\text { platform matching their needs } \\
\text { and values to read, curate, fil- } \\
\text { ter, prioritise, and respond to } \\
\text { items in their chosen feeds, } \\
\text { replying to or "liking" items } \\
\text { from their friends, family and } \\
\text { colleagueson large platforms. } \\
\text { Civil society groups can de- } \\
\text { velop tools to help users filter } \\
\text { and prioritise feeds in a way } \\
\text { that better reflects their val- } \\
\text { ues than standard large plat- } \\
\text { form user interfaces. }\end{array}$ & $\begin{array}{l}\text { Explicit ex ante DMA rule. } \\
\text { EC standardisation recogni- } \\
\text { tion relating to W3C Activity- } \\
\text { Pub. } \\
\text { Enforced by DG COMP/ other } \\
\text { EU digital market agency/na- } \\
\text { tional competition authorities. }\end{array}$ \\
\hline $\begin{array}{l}\text { User can access closed mes- } \\
\text { saging/sharing groups organ- } \\
\text { ised on other platforms, with } \\
\text { permission of those groups' } \\
\text { organisers (at users' own ini- } \\
\text { tiative). }\end{array}$ & $\begin{array}{l}\text { Users can choose any tool or } \\
\text { platform matching their needs } \\
\text { and values to participate in } \\
\text { social groups online, avoiding } \\
\text { exclusion. }\end{array}$ & $\begin{array}{l}\text { Explicit ex ante DMA rule. } \\
\text { EC standardisation recogni- } \\
\text { tion relating to W3C Activity- } \\
\text { Pub and relevant messaging } \\
\text { standards. } \\
\text { Enforced by DG COMP/EU } \\
\text { digital market agency/ na- } \\
\text { tional competition and au- } \\
\text { thorities. }\end{array}$ \\
\hline $\begin{array}{l}\text { A dominant platform should } \\
\text { inform users of alternative } \\
\text { apps/services whenever it of- } \\
\text { fers to install its own app/ser- } \\
\text { vices (no self-preferencing), } \\
\text { and inform prospective users } \\
\text { about alternative intercon- } \\
\text { nected platforms when }\end{array}$ & $\begin{array}{l}\text { Users are given free, unbi- } \\
\text { ased choice of tools they use } \\
\text { to access popular services. } \\
\text { Users can get access to new } \\
\text { components and functionality } \\
\text { (whether complements or } \\
\text { substitutes) developed for }\end{array}$ & $\begin{array}{l}\text { Explicit ex ante DMA rule/ } \\
\text { Strengthen } 66 \text { P2BR for dom- } \\
\text { inant platforms } \\
\text { Enforced by DG COMP/EU } \\
\text { digital market agency/ na- } \\
\text { tional competition authorities. }\end{array}$ \\
\hline
\end{tabular}




\begin{tabular}{|c|c|c|}
\hline $\begin{array}{l}\text { suggesting they create an ac- } \\
\text { count. }\end{array}$ & $\begin{array}{l}\text { large platforms that better } \\
\text { match different user group } \\
\text { preferences. }\end{array}$ & \\
\hline $\begin{array}{l}\text { Development of new, inde- } \\
\text { pendent services that make } \\
\text { use of users' profile and be- } \\
\text { havioural and inferred data, } \\
\text { previously controlled by dom- } \\
\text { inant platforms. }\end{array}$ & $\begin{array}{l}\text { User's own choice of tools } \\
\text { can filter and prioritise feed } \\
\text { items based on their, and } \\
\text { other tool users', historical } \\
\text { feedback and preferences. }\end{array}$ & $\begin{array}{l}\text { Enabled by explicit ex ante } \\
\text { DMA, updated GDPR } \$ 20, \\
\text { ePrivacy Regulation, and/or } \\
\text { Data Act rule. } \\
\text { EC-initiated standardisation } \\
\text { activity and recognition. }\end{array}$ \\
\hline $\begin{array}{l}\text { Developers can use anony- } \\
\text { mized, aggregated data of } \\
\text { large groups of other users } \\
\text { and/or statistical models } \\
\text { trained by dominant plat- } \\
\text { forms to improve their ser- } \\
\text { vices. }\end{array}$ & $\begin{array}{l}\text { Users are able to choose } \\
\text { tools, which can filter and pri- } \\
\text { oritise feed items based on } \\
\text { very large amounts of data } \\
\text { and models from dominant } \\
\text { platforms (e.g.about popular- } \\
\text { ity of millions of different web } \\
\text { pages and media clips). }\end{array}$ & $\begin{array}{l}\text { Enabled by explicit ex ante } \\
\text { DMA and/or Data Act rule, or } \\
\text { strengthening of P2BR } § 9 \text {. } \\
\text { EC-initiated standardisation } \\
\text { activity and recognition. }\end{array}$ \\
\hline
\end{tabular}


Interoperability as a Tool for Competition Regulation

lan Brown

This paper is published with the OpenForum Academy, which is an independent programme established by OpenForum Europe. It has created a link with academia in order to provide new input and insight into the key issues which impact the openness of the IT market. Central to the operation of OpenForum Academy are the Fellows, each selected as individual contributors to the work of OFA.

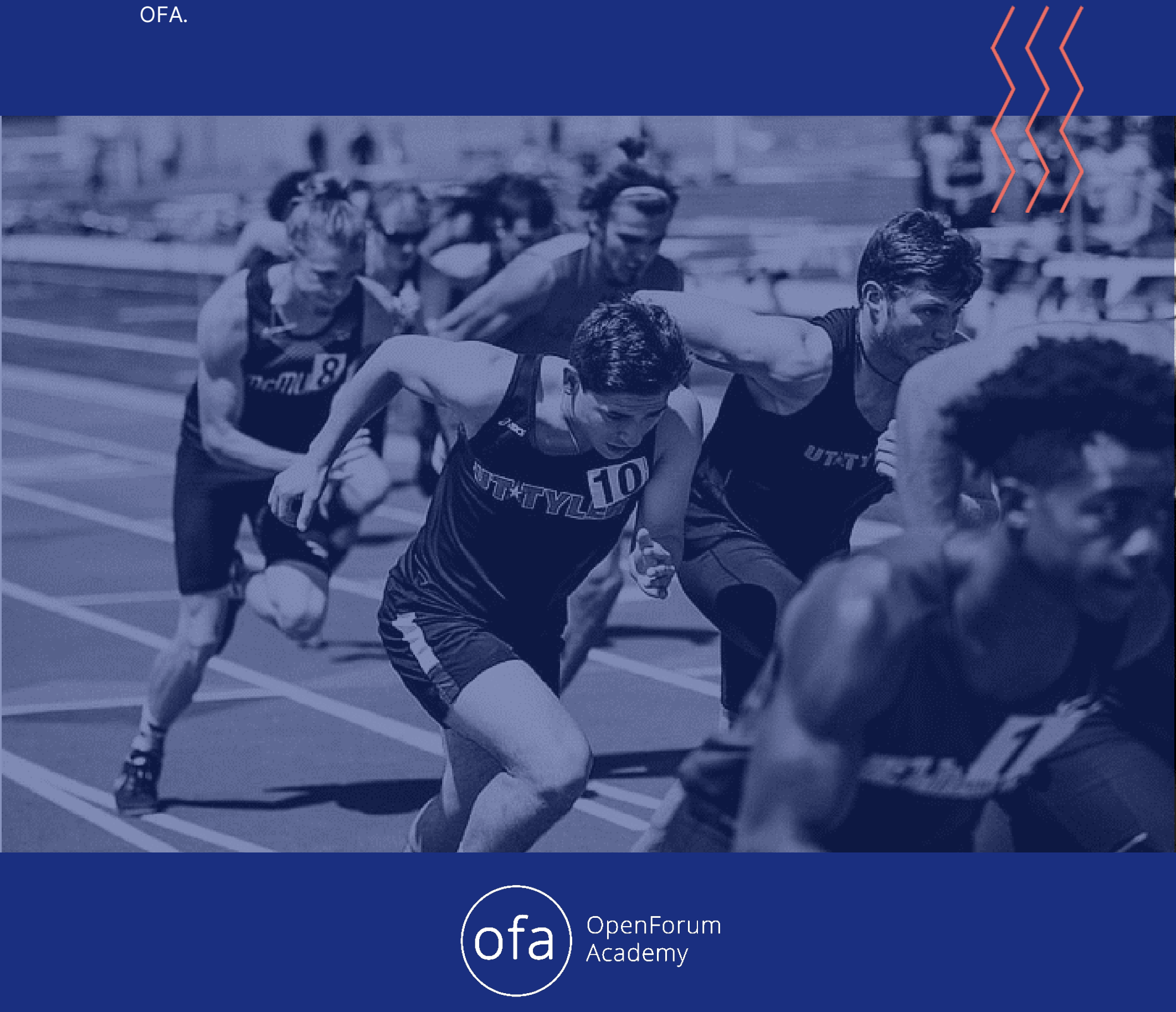

